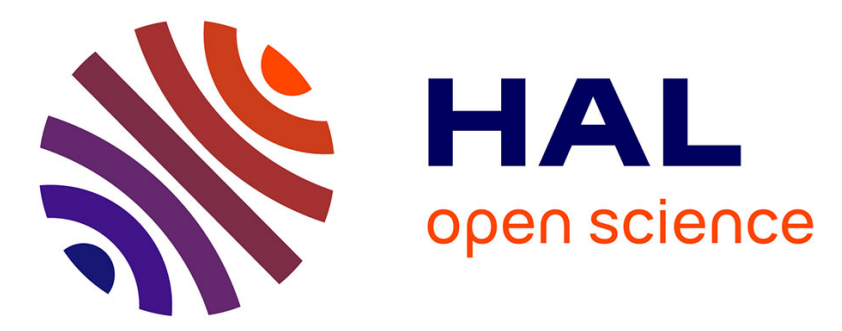

\title{
L'about inscrit du musée national du Cambodge (K. 943) : nouveaux éléments sur le bouddhisme tantrique à l'époque angkorienne
}

\author{
Julia Estève, Brice Vincent
}

\section{- To cite this version:}

Julia Estève, Brice Vincent. L'about inscrit du musée national du Cambodge (K. 943) : nouveaux éléments sur le bouddhisme tantrique à l'époque angkorienne. Arts Asiatiques, 2010, 65 (1), pp.133158. 10.3406/arasi.2010.1710 . halshs-02477470

\section{HAL Id: halshs-02477470 \\ https://shs.hal.science/halshs-02477470}

Submitted on 12 Mar 2020

HAL is a multi-disciplinary open access archive for the deposit and dissemination of scientific research documents, whether they are published or not. The documents may come from teaching and research institutions in France or abroad, or from public or private research centers.
L'archive ouverte pluridisciplinaire HAL, est destinée au dépôt et à la diffusion de documents scientifiques de niveau recherche, publiés ou non, émanant des établissements d'enseignement et de recherche français ou étrangers, des laboratoires publics ou privés. 


\title{
L'about inscrit du musée national du Cambodge (K. 943) :
} nouveaux éléments sur le bouddhisme tantrique à l'époque angkorienne

\author{
Julia Estève, Brice Vincent
}

\begin{abstract}
Registered by the National Museum of Cambodia in 1933 and still unpublished, the inscription K. 943, engraved on a bronze end-piece, provides interesting information about the date of the object as well as the religious history of the Khmer country and, more specifically, Buddhism. Although it is difficult to understand, this unusually long inscription for a metal Khmer object mentions a single deity, the Kamraten Jagat Chpār Ransī, who appears in a dozen Khmer inscriptions, suggesting that he was an important deity during the Angkor period. Several elements of the text indicate a late Angkorian date, as opposed to a hasty analysis of the object which could lead one to believe otherwise, and thus supply the most recent evidence of this renowned Buddhist deity. Moreover, by virtue of the deity it bears - a Vajrasattva - this finial links the Kamraten Jagat Chpār Ransī with Tantric Buddhism and, by doing so, raises some new questions about the development of this specific way of Buddhism in Khmer history.
\end{abstract}

\section{Citer ce document / Cite this document :}

Estève Julia, Vincent Brice. L'about inscrit du musée national du Cambodge (K. 943) : nouveaux éléments sur le bouddhisme tantrique à l'époque angkorienne. In: Arts asiatiques, tome 65, 2010. pp. 133-158;

doi : https://doi.org/10.3406/arasi.2010.1710

https://www.persee.fr/doc/arasi_0004-3958_2010_num_65_1_1710

Fichier pdf généré le 08/11/2019 


\section{Julia Estève et Brice Vincent}
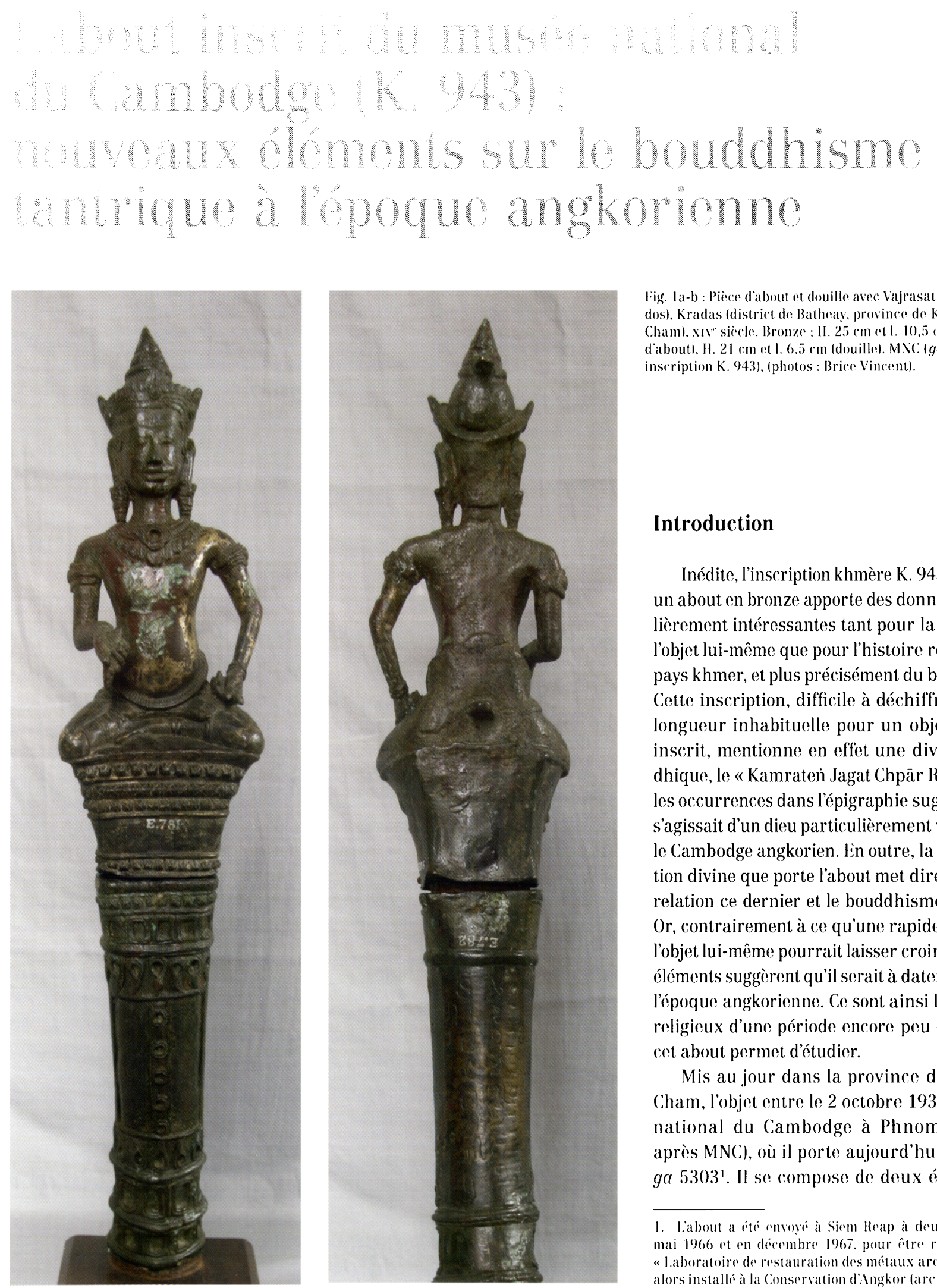

Fig. 1a-b : Piece dabout ot douille avee Vajrasattva (face al dos). Kradas (distriet de Batheay, province de Kompong Cham). XIr" siècle. Bronze: II. $25 \mathrm{~cm}$ et $1.10,5 \mathrm{~cm}$ pièce daboutl, $11.21 \mathrm{~cm}$ ot I. $6.5 \mathrm{~cm}$ (douille). MNC (ga 5303 ; inscription K. 943), (photos : Brice Vincent). 
bronze, tous deux fondus en creux par le procédé de la « cire perdue » et destinés à être assemblés l'un à l'autre: un about de $25 \mathrm{~cm}$ de long et 10,5 $\mathrm{cm}$ de large, qui porte une image de divinité bouddhique, et une douille de section ovale de $21 \mathrm{~cm}$ de long et $6,5 \mathrm{~cm}$ de large (fig. 1a-b). Ia face postérieure de la douille est gravée d'une inscription de cinq lignes dont nous présentons ici l'édition et la traduction. l'objet lui-même a été publié plusieurs fois sans que la présence d'une inscription n’ait été relevée pour autant².

\section{Une divinité du bouddhisme tantrique : Vajrasattva}

La divinité est représentén assise en attitude noble (sattwaparyanka), les jambes croisées l'une sur l'autre. Le bras droit est légèrement écarté de la poitrine, alors que le bras gauche est plié et repose sur la hanche gauche. Les deux mains portent chacune un attribut : malgre l'état d'usure de la pièce, il semble possible d'identifier un foudre (eajra) pour la main droite, dont la paume est tourné vers le haut, et une clochette (ghantā) pour la main gauche (fig. 2a).

Cette iconographie correspond à la représentation traditionnelle de Vajrasattva, une divinité du bouddhisme tantrique, et non de Vajrapāni comme le mentionnaient jusquici la plupart des publications3. Ceorge coedes a eté le premier à identifier ce type iconographique dans l'art du Cambodge ancien et à publier des images khmòres de

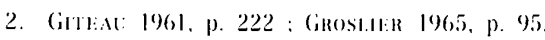

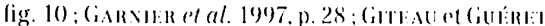

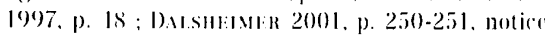

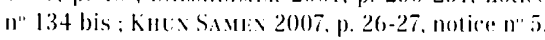
Bien que George (iroslier ait signale l'inseription sur la fiche d"imentaire de la douille (n" I: 722 ) même šil ni royait que quatre lignes -, il semble quiolle fut oublié pendant quelgue temps. re qu

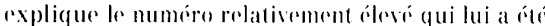
altribue par cerorge cades dans le volume vall de ses Inscriptions du Cambodge (IC VIII. p. 216-217).

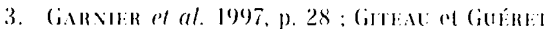
1997 , p. 18 : DALsHeImen 2001, p. 250-251 kntix Samex 2007. p. 26-27. Cette identification a Vajrapañ a éte d'abord proposére dans l'un: des

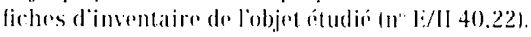

Vajrasattva, se fondant sur des exemples analogues alors connus dans riconographie bouddhique tant indienne que tibétainet. Pour bien comprendre l'importance de cette nouvelle identification, il convient de replacer la divinité Vajrasattva dans le contexte du bouddhisme tantrique khmer.

\section{Le développement du bouddhisme tantrique: de l'Inde au Cambodge}

$\grave{\Lambda}$ partir du milieu du $\mathrm{I}^{\mathrm{rr}}$ millénaire, la religion indienne s'enrichit d'un corpus de textes tantriques, catalogués ultérieurement comme tantra. Ie bouddhisme mahāyāna semble avoir intégró ces textes et les rituels qui leur sont afférents pendant les premiers développements de ce qui devient plus tard le bouddhisme tantrique ou ésotérique (Vajrayāna). C’est apparemment vers le milieu du vı" siècle que le bouddhisme tantrique indien commence à connaître une existence indépendante en tant que système religieux constitue". Son développement connaît ensuite plusieurs phases qui se mettent en place progressivement et ne sont pas exclusives l'une de l'autre : tout d'abord, du vilr" au $x^{\prime \prime}$ siecle so déploie le panthéon des Yoga Tantra, avec: Vairocana et Vajrapāṇi-Trailokyavijaya à sa tête, puis, du $\mathrm{X}^{\prime \prime}$ au XIII" sieccle apparaît le panthéon des Anullara Yoga Tantra, centré sur les divinités féroces, dont Hevajra".

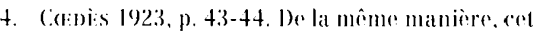
atuteur identilia et publia pour la premiere fois des images khmores de Vajradhara, une autre divinite du bouddhisme tantrique portant les deux mêmes attributs que Vajrasattva, soit le rajra et la clochette, mais aver les deux mains croisces sur la poitrine libid.. p. 43-441.

5. Subhakarasimha (6.37-735), Vajabodhi 6071 $7+11$ ot Amoghavajra $(705-7 i+1$ furent les portoparole principaux du mouvement Vajrayaina H.ANOTTE 1966, p. 150).

6. Vous suivons ici l'analyse en le découpage tempores de Robert linrothe (1999), qui définit trois phases de developpement do Vajrayana en Inde dans la premiere, il noest encore quoblements

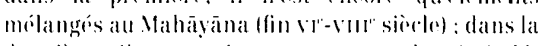
deuxiome, il se constiture en lant que chemin independant din vall"-lin s" siècle) : enfin, il sexprime

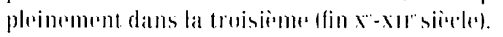

Suivant le développement indien, ce courant du bouddhisme se retrouve au Cambodge, où il s’implante au cours de l'époque angkorienne, tout d'abord de façon parallele au bouddhisme mahāyāna. Plusieurs inscriptions attestent ce dernier sur lo sol khmer, à commencer, au x" siecle, par l'inscription K. 111 de Vat Sithor (947-948) et les inscriptions K. 266-268 de Bat Cum $(953-954)^{*}$. Ces premiers témoignages montrent le bouddhisme tantrique comme encore peu distinct du Mahāyāna. Sous le règne de Jayavarman V, il entrerail dans une premiere phase d'expansion. Au xI" siecele, les inscriptions K. 2:30 de Prasat Beng (1026-1027)" et K. 1158 de Sab Bak (1067 : cl. infra p. 136) attestent. en particulier, cette évolution. linfin, à la fin du xir" siecele, le bouddhisme tantrique se développe vers des formes hautement ésotériques, centrées notamment sur Ilevajra, l'une des figures clés des Yoginülantra ${ }^{10}$.

7. I.inseription réborbre Kirtipandita, äcerye du souverain Javavarman V (r. (a. $968-1000 \cdot 1)$, qui r'st présente comme le guru des rois at des reines, sämlahpuraih rājabhir yyo gurükrtah lst. XXXII : 1\%. p. 195) : ce: personnage ritait un bouddhistr frepvent, suivant fe Mahayana el peut-ître plus partieulierement le Vantrayăna. La stance XXIII parle de séquences quaterna ires le dévour a la méditation aux quatre jointures du jour, donateur des quatre dons. un avee les quatre mudrä. il enseignait le Dharma aux quatre congrégations »). dont quatre mudrā qui. selon Alexis Sanderson (20)3-20(1) p. 427). sont une marque caractéristique du Mantrayāna linfin, l'ins-

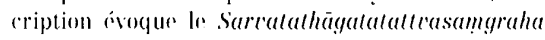
érit principal de l'école Yogatantra dont le titre serait iei abrége, et son commentaire.

8. Solon ces inscriptions, le ministre du souverain Räjendravarman (r. 944-968). Kavindrärimathana. fonda. entre autres, une image de Vajrapāni. De plus, la stance $X X X$ de K. 267 alfirme que Kavindrärimathana avait "réalisé l'union carareterisée par lidentite de son propre esprit avee la nalure divine du Buddha " $1($ cotot:s 1908, p. 2131. or, selon Robert linrothe (1999), p. 146), ciest a partir de la seconde phase de son developpement que le Vajrayāna adopte l'idéo qu'il est possiblr d'atteindre l'Illumination ultime et la Buddhéiti dans ce monde-ci. Innfin. un yantra découvere sur li site de Bat Cum incite a penser que lo bouddhisme

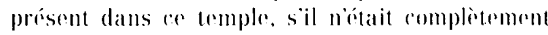
tantrigue, comportait du moins des ciliments tanAriques (woir (c):oi:s 1952).

9. l.es stances d'invoration de l'inseription sont consacrées, notamment. à lokeśsara ret à Vajeapani (IC. VI. p. 241$)$

10. sAxm:kson 2003-2004, p. 424, 11. 277 . 

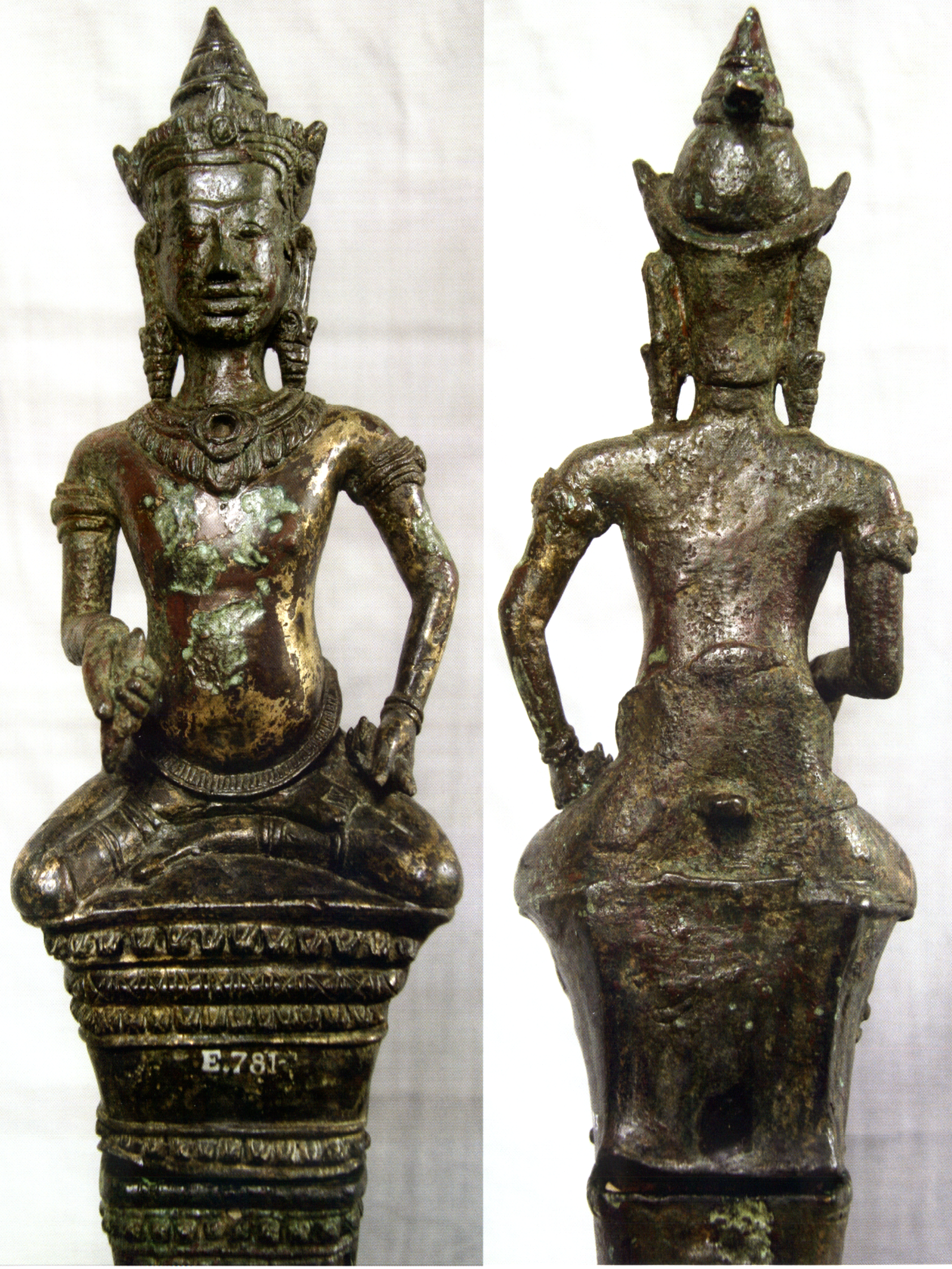
Vajrasallua / Vajrapāni :

theologie el iconographie

Au sein de ces développements, plusieurs divinites se rencontrent et, notamment, la divinité étudiée dans le présent article, Vajrasattva" ${ }^{11}$. Solon Alfred Foucher, celle-ci est, dans le bouddhisme indien, une "sorte de divinité suprême, supérieure aux I)hyâni-Bouddhas Iles cinq Buddha transcendants ou jinal et portion de l'Âdi-Bouddha lou Buddha primordiall, incarnation de l'intelligence souveraine qui dirige l'univers ${ }^{12}$. Vajrasattva semble acquérir une place majeure dans le système tantrique lors de la seconde phase de constitution de ce courant du bouddhisme, soit le $\mathrm{X}^{\prime \prime}$ siècle ${ }^{13}$. Quant à la divinité nommée Vajrapāṇi ${ }^{14}$, son parcours dans Ie bouddhisme tantrique peut etre retracé comme suit : elle est d'abord une « forme secondaire d'Indra ", puis le "génie protecteur do Śākyamuni » et un « bodhisattva attaché avec $\bar{\Lambda}$ nanda au service du Maître ", avant de devenir une "divinité émanée de l'ître suprême $»^{15}$.

Comme nous l'avons vu, cette antériorité de Vajrapāṇi se retrouve dans l'épigraphie khmère, puisque, dès le $x^{\prime \prime}$ siecle, les inscriptions K. 266-268 de Bat Cum ou encore K. 230 de Prasat Beng rapportent des fondations de statues representant cette divinité La plus ancienne oceurrence du terme « Vajiasattva » n'apparaît, en revanche, que dans la seconde moitié du XI" siècle dans l’inscription K. 1158 de Sab Bak. Lïntógralité de son mangala s’adresse à des divinités bouddhiques ${ }^{16}$. la premiere stance est adressée aux cinq Buddha transcendants (jina) que sont Akṣobhya, Amitābha, Amoghasiddhi. Ratnasambhava et Vairocana. la seconde

11. " (Coluil qui a le diamant pour essener $\Rightarrow$ (I)t Matrmaxi 1975, p. +19$)$.

12. Fotcher 1900. p. 123, citri dans (abois 1923 . p. 38 .

13. BHothonakm 1964, p. 127-128.

14. "Yain aut rejira lou : " Foudere en main ») (1) MA1.MAN 1975, p. +13$)$

15. I.А.

16. (H)RApat PBapaxovims 1990, p. 11-14 1.silite 2009, p. $4+2-4.22$. est dédiée à Vajrasattva, présentó comme le « Sixième (Buddha) »'̄. (Or, selon David Snellgrove, le sixieme Buddha ou Buddha suprême porte indifféremment le nom de "Primary Buddha $(\bar{A}$ dibuddha) or (ireat Vairocana or Vajra-Being (Vajrasattva) or whatever title may be used ", en fonction des différentes traditions tantriques concernées's. Ainsi le terme «Vajrasattva » dans l'inscription K. 1158 semble bien être un théonyme faisant réfí. rence au Buddha suprême. I)es la seconde moitió du XI" siecele, Vajrasattva aurait donc été vénéré dans le bouddhisme tantrique khmer comme le sixième Buddha. superieur aux cinq Buddha transcendants. Il n'est toutefois pas impossible que sa position au sein de ce courant religieux ait évolué au cours des siecles suivants, comme en témoigneraient des images plus tardives de la divinité (cf. infra p. 141).

la découverte de linscription K. 1158 étant récente, il est à noter que Vajrapāni est longtemps resté la seule divinité tantrique mentionnée dans l'épigraphie khmère. En raison de ce silence des textes, George Coedes a pensé pouvoir réunir les diverses images quill identifia d’après leur iconographie comme des Vajrasattva et des Vajradhara « sous la dénomination unique de Vajrapāni ", dont ces deux divinités n’auraient été que des "suecédanés »"19. ()r.

\section{Stancer}

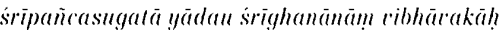

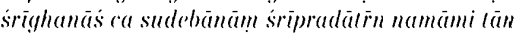
"Les (ong Buddlat equi. à l'origine. furent les createurs des Sröghana ed tsont eux-mêmesl les Srïgham des excellents dieux, je me prosterme devant eux qui sont les donateurs de gloiren.

Stancer I].

bajrasatras Iu șasthah sadrodhisateaprabhur rarah ädhäral sarrainddhämäm! lan namämi vimukta!ye "Vajratsallva. le Sixieme: (Buddhal. qui est l'excellent maîtere des Bodhisativa existants ot le porteur de tous les Buddha, je mineline devant lui pour la délicrances.

I8. Sivit.cinovi: 1987, p. $20 \bar{i}$

19. Cants 1923, p. 43. Coter hypothise fut plus

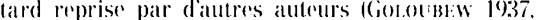
p. 97-98; Bolssit1.1:R 1951. p. 324). II ne faut pas plus oublier fe terme cajrim, "renlui qui porte un exijra».

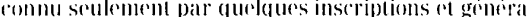

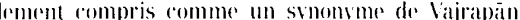
dans rente même perspertive dianalogie entre divinite tantriques (Boissi:III:R 1966, p. 304. n. 2l. Copendant.

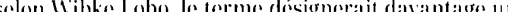
forme precoese de la divinite llevaja $(1997$, p. 78$)$.
Vajrapāṇi et Vajrasattva ont bien chacun fait l'objet de représentations qui se sont développées à des époques différentes. confirmant par là les donnécs ćpigraphiques. In effet, si Vajrapāṇi apparaît dans l'iconographie khmère dès la seconde moitié du $x^{\prime \prime}$ siècle, en particulier sur des stèles bouddhiques (caitya), Vajrasattva ne: commence à être représenté qu’à partir du siècle suivant, sous la forme de statuettes en bronze?" Parmi ces premières images. il faut citer, en particulier, un Vajrasattva conservé au MNC: ( ga 2647 et 2657) et daté de la seconde moitié du XI" siècle. Ce bronze: montre la divinité assise sur un trône avec: dans son dos, un chevet mobile circulaire surmonté d'un parasol21 (fig. 3). D'autres représentations, toujours en bronze mais souvent incomplètes, sont ensuite attestées au xir" siècle et, au moins, jusquau siecte: suivant ${ }^{22}$.

20. Desux images plus anciennes de Vajrasattla. (clles

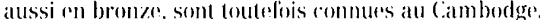
mais il sagit clairement dobjets importis. liume. decouserte dans la provinere do Kandal et conservé

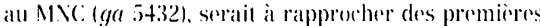
representations indiemenes de la divinité, en particulier

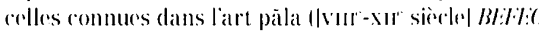
$34(2) \mid 1934$. p. 749. pl. 17-13 : Sil.arroock 2006, p. 46-47, pl. 1t, ou lat piece est identifiée, alu contraire. comme

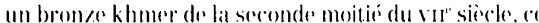
qui en fait pour latuleur " the earliest khmer ieon that

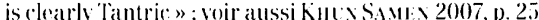
notice 11" 31. I ln bronze en tous points identique, mais malheureusement sans provenance comnue, se trouve à la National Gallery of Australia de Canberma 168.111 ; BARXARI 1978. p. 13-14. pl. 6 a 10). Kautre image importere conserver à leorigine all sein dune collection privere de Phom Ponh avant davoir éte acquise par le Cleveland Muse'um of 'Art 11947.494), serait, quant a

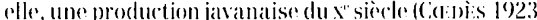

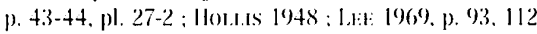

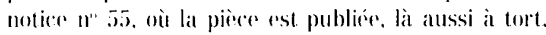
romme un bronze khmer du xir"-xull sienlel.

21. Colizbis 1988, p. 23, fig. 19.

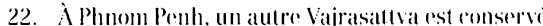
au MNC (ga 202), alors quan exemple prescyur similatere à notere piere se trowad - et se trouse peut-être pmeore - dans les collections du Palais Royal l(ci:uj: 1923 p 43-44 pl 28-2 ou la piere est publice pour lia

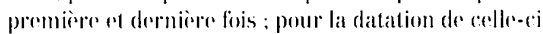
cf. infra n. s2l. Plusirurs autres images de la divinite se repartissent entre les collections de's musres nationaux de 'Thaillande : a Bangkok (I.B.12 en L.B.13). Phima 1483.2535). I. (npburi 1.V.K1..5721, ou encore Songkhla

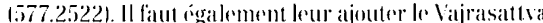

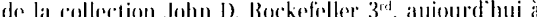
lisia Society de Vew lork 11979067 . I. a plupart des autres image's semblent être conservés alu serin de col-

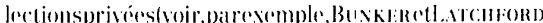
2004. p. $416-417$, notice n" $\left.14^{9}\right)$. 


\section{Iconographie, slyle el technique?}

Suivant la même iconographie que ces statuettes, le Vajrasattva ic:i étudié est également assis sur un trône, de forme trapézoïdale et à plusieurs registres décorés, entre autres, de feuilles de lotus. Ce même décor réapparaît sur la douille mais seulement au niveau de l'extrémité supérieure de celle-ci. Par ailleurs, un chevet mobile venait, là aussi, compléter l'ensemble. Seuls en témoignent un léger décrochement visible au-dessus de la face postérieure du trône et deux tenons en boucle aménagés à l'arrière de la tête et dans le bas du dos (fig. 2b). Ces tenons étaient à l'origine destinés à assurer la fixation du chevet, sans doute au moyen d'une tige en fer. Un autre type d'assemblage, lui aussi mécanique, aurait été choisi pour réunir l'about et la douille : en labsence de tenons, il est possible qu'une simple pièce en bois dont la forme épousait l'intérieur de chacun de ces deux éléments leur ait permis de s'emboîter l'un dans l'autre"2.

la présence d'un chevet explique que le vêtement et la parure du Vajrasattva n’aient pas été représentés dans le dos mais seulement de face et sur les côtés. Il en est d'ailleurs de même pour le décor du trône. Coiffée d’un diadème-couronne à fleurons que complète un couvre-chignon conique (mukuta), le dieu au torse nu est vêtu d'un long sampot lisse dont le bord supérieur se rabat tout autour. Il porte

23. Nous souhaitons memereier ici. pour nous avoir permis dobserver directement la piece étudiée et de la photographier. Huot Samnang et le Metal Conservation laboratory du $\mathrm{WVC}$.

24. Pour rentorcer cet assemblage. l'about chat pereri au niveau du trône de deux trous diamétralement oppesés de section ronde. aujourd hui masqués par une restauration à liepoxy mais visibles sur des photographies darehises montrant lobjet retudie llounds Cambodge de la photothéque de

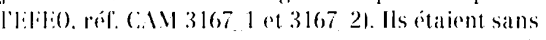
doutr destines à recevoir une tige en fer servant a maintenir en place la piece ron bois. Lne autre tige ren fer serail venue sonscerer dans la partie superieure de la douille, ou deux trous plus irréguliers

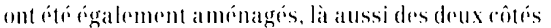
de la piece. Enfin, il faut rappelere que la piere en bois alujourd hui lichée dans labout est un ajout moderne des mestaurateurs.

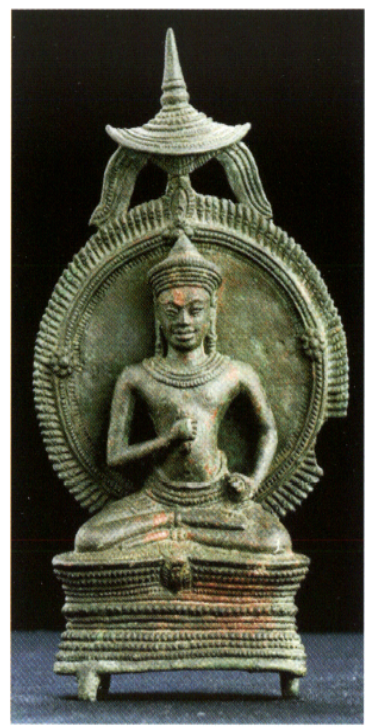

lig. 3 : Vajrasattva. Srah Srang. Angkor (province de Siem Reap). Seconde moitié du $\mathrm{xu}^{\prime \prime}$ siècle.

Bronze, H. $15.5 \mathrm{~cm}$

M.VC: (gat 2647 et 26557 ), (photo : M.VC).

également une riche parure, composée à la fois de pendants d'oreilles, d'un collier pectoral, de brassards et de bracelets, d'une ceinture et d'anneaux de chevilles. Le chevet explique aussi que seule la partie visible de l'about ait été recouverte d'une couche de dorure, dont d'importants vestiges sont encore observables, aussi bien au niveau de la divinité que de. son trône. Lanalyse par fluorescence X (XRF) de la couche de dorure recouvrant, en particulier, le ventre de la divinité a permis de mettre en évidence de faibles traces de mercure, preuve évidente qu'une dorure au mercure, aussi dite à l'amalgame de mercure, a été appliquée sur labout lors du travail de finition (fig. 2a). En revanche, plusieurs autres analyses réalisées dans le dos de la divinité ainsi qu'au niveau de la douille n'ont pas révélé de telles traces ${ }^{25}$.

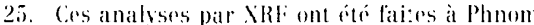
Penh en derembere 2009 par Thomas chiser pryere du Researeh laboratory for Irehacology and the Ilistory of Art (oxford Iniversity). I.interprótation des donnés a ete. en outre. rendue posible grâter a laide de bavid Bourgatrit du centre de recherehe ent do restaturation des museres de liraner.
Quant à la douille, sa face antérieure se distingue par un décor très élaboré, constitué de plusieurs registres plus ou moins symétriques et rehaussés à l'origine de nombreuses incrustations. Il est possible. de dénombrer trente-quatre logements au total, de forme carrée, rectangulaire, ronde, ou encore lancéolée. La profondeur de ces cavités indiquerait qu'elles ont très certainement reçu des pierres, précieuses ou semi-précieuses, même s"il semble que d'autres matériaux aient été également utilisés pour incruster les bronzes khmers (métaux - précieux ou non-, verre, nacre, ou encore émaux). Il en était sans doute de mêmo pour la cavité ronde qui orne le fleuron central du collier de la divinité. Enfin, les deux « compartiments » rectangulaires qui décorent la partie centrale de la douille montrent sur leur pourtour des rainures, où des feuilles d'or ont été insérées, avant d'être martelées. Quelques restes de ces feuilles d'or ont été identifiés après examen au microscope optique, alors que la surface de chacun des « compartiments » porte encore les traces du travail de martelage. Il s'agit là d'un nouvel exemple de dorure par gainage à la feuille, une technique attestée seulement par quelques bronzes à l'époque angkorienne²0. Un grand soin semble donc avoir été porté à la réalisation de cette douille.

\section{Abouts, enseignes et pavois : nouvel aperçu des pratiques rituelles du bouddhisme tantrique}

\section{Un about d'enseigne bouddhique?}

Dans plusieurs des fiches d'inventaire relatives à l'objet étudié (n" E/II 40,22-23), ce dernier est identifié, sans plus de précision, comme un « about». Selon Jean Boisselier ${ }^{27}$, ces abouts ou pièces d'about. toujours en bronze, auraient joué deux

26. less deux premiers exemples identilies ont éte signales par cieorge Cirosliere (1924, p. 70-71, 98: 1931, p. 102, pl. 38-11: il sagit done tête discete (rsi) ret d'un bras de stallue. leus deus ronserves all VIVC (respertivement ga 5288 et ga $5+24)$.

27. Bolsstiltik 1966. p. 338-341. 


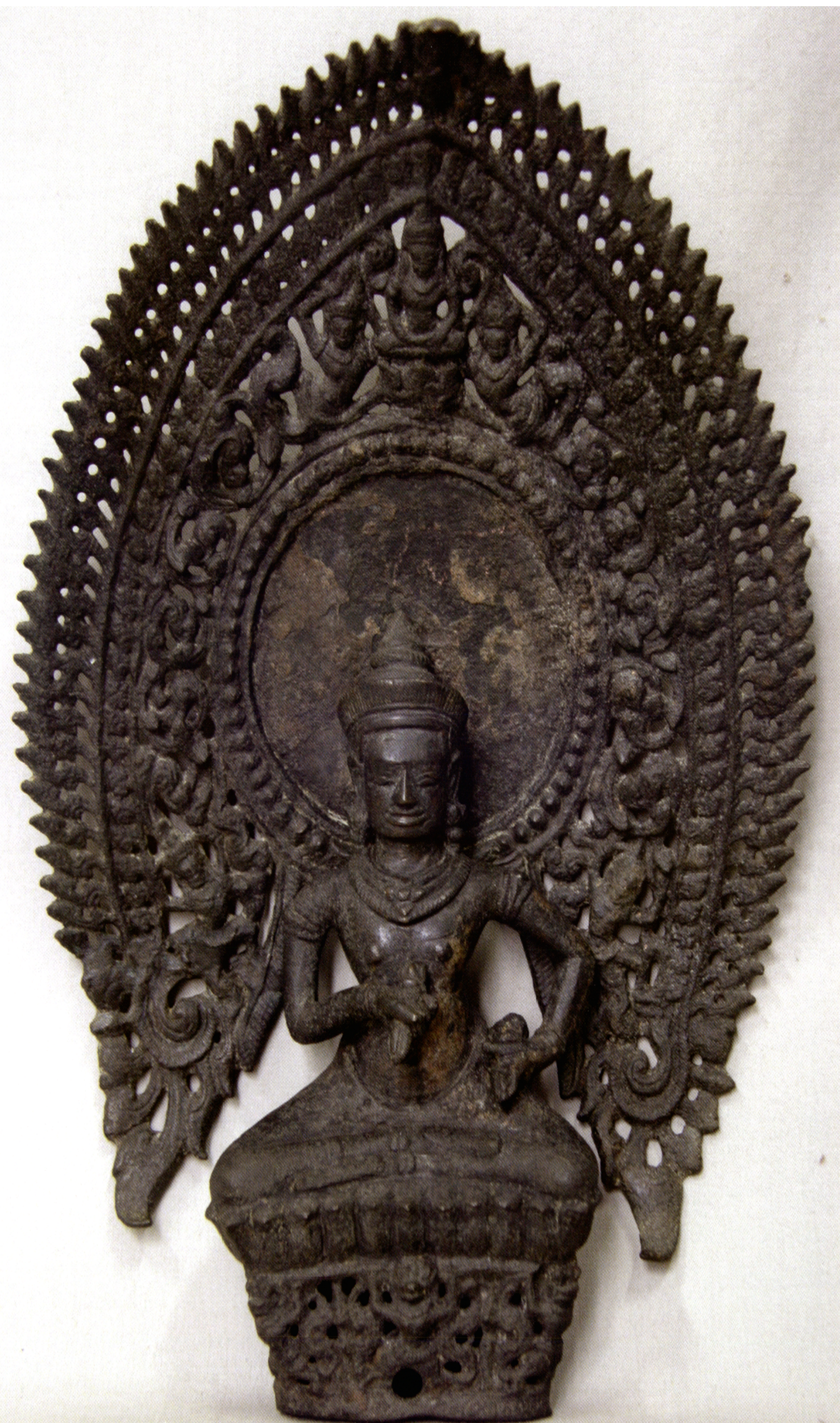




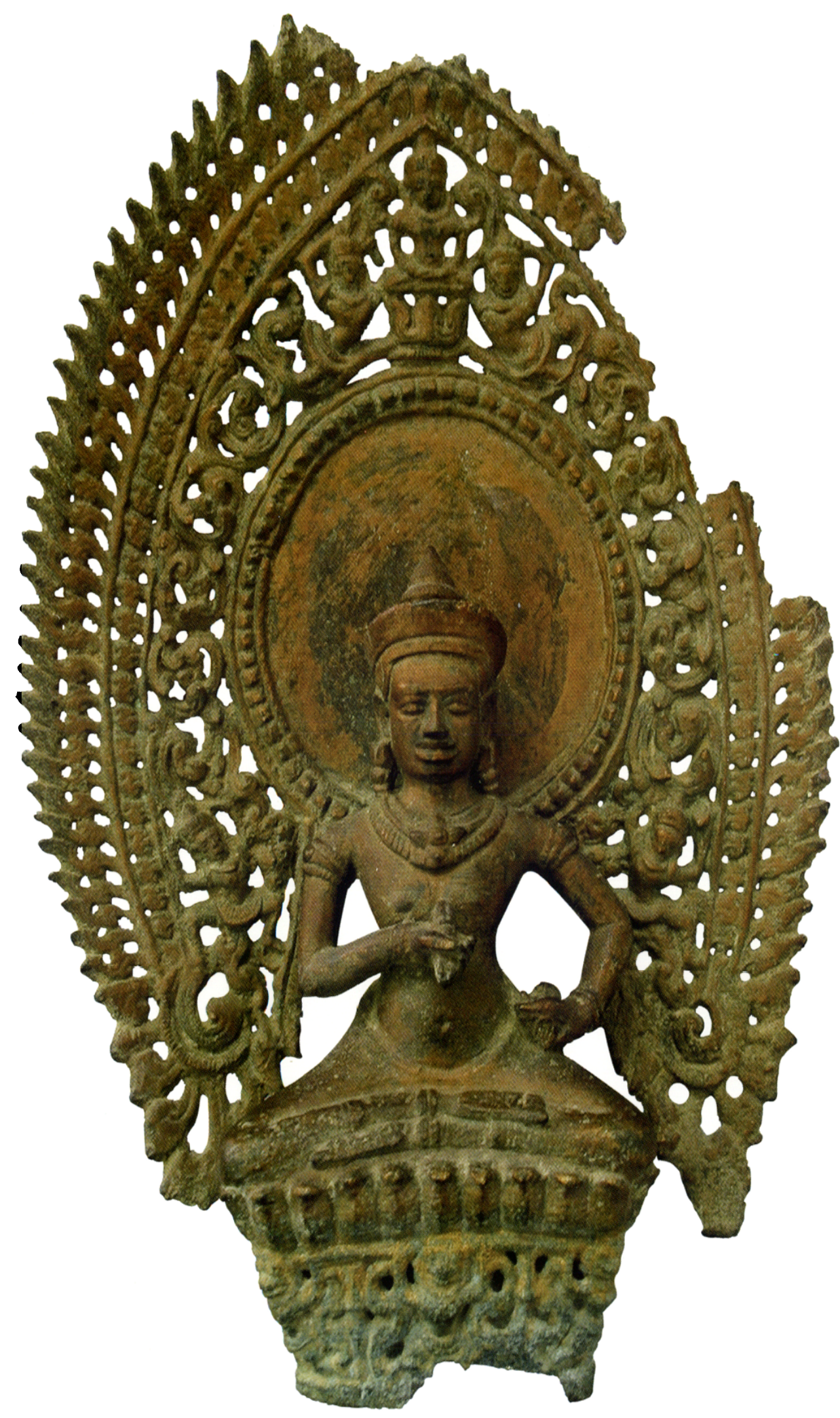

fonctions majeures : la plupart auraient servi déléments de véhicules (extrémités de timons ou de brancards), alors que d'autres, plus rares, auraient eu « une destination cultuelle plus précise, encore qu'indéterminée, ${ }^{28}$. Seule la première fonction a été retenue dans les diverses publications mentionnant notre pièce ${ }^{29}$.

Cependant, sa forme légèrement incurvée la distingue clairement des extrémités de véhicules dont le profil est toujours en $S$ très allongé, comme en témoignent. notamment, les bas-reliefs des XII"-XII" siècles. Sa morphologie, tout comme le décor de son motif terminal qui figure une image divine, semblent, en revanche, mieux correspondre à un about à destination cultuelle. Ainsi, à ce stade de l'étude, nous posons l'hypothèse d'un about fiché au sommet d'une hampe vraisemblablement en bois, qui aurait été porté dans le cadre de processions. En ce sens, la première identification proposée par George Groslier, qui voyait en l'objet étudié une «enseigne » (fiche d'inventaire n" I: 781), est peut-être à reconsidérer, en précisant que celle-ci n'aurait pas été militaire mais religieuse ${ }^{30}$. Si l'épigraphie ne nous fournit pas d'élément probant sur la fonction ou le nom de ce type de pieces, le terme dandạgara, «pointe de bâton »"31, que l'on rencontre dans le corpus pourrait, selon nous, $y$ faire allusion ${ }^{32}$.

28. Comme le rappelle Jean Boisselier 1966. p. 338. n. 1), une telle destination avait bó déja pressentie par George Cordes (1923, p. 38, 51, 53, pl. 39) a propos d'un de ces abouts quil avait identifie romme un "porte-cierges " et rapproche des popil ou chandeliers rituels cambodgiens modernes.

29. (imeau 1961, p. 222 k about do timon ") : (jkost.ne 196.5, p. 95 (« About de timon de chal $»)$ : Giariler el al. 1997, p. 28 le décor d'about de timon

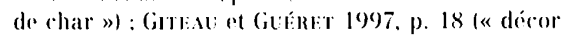

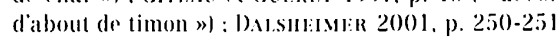
("About de timon (?)").

30. Comme en témoignent les memes bas-reliefs. les rnseignes militaires figurent lo plus souvent soit des personnages masculins ou encore le singe llanuman en attitude de combat ou de danses soit Garuda en attitude de pré-encol ret portant parfois Visnu (roir Borssti.1: R 1966. p. 342-343. pl. 59-3 :

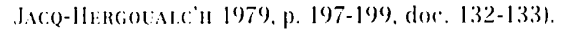
31. Pov 2004. p. 244.

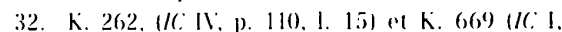
p. 170. 1. 2.57 : voir aussi SolTut 2009, p. 126. 


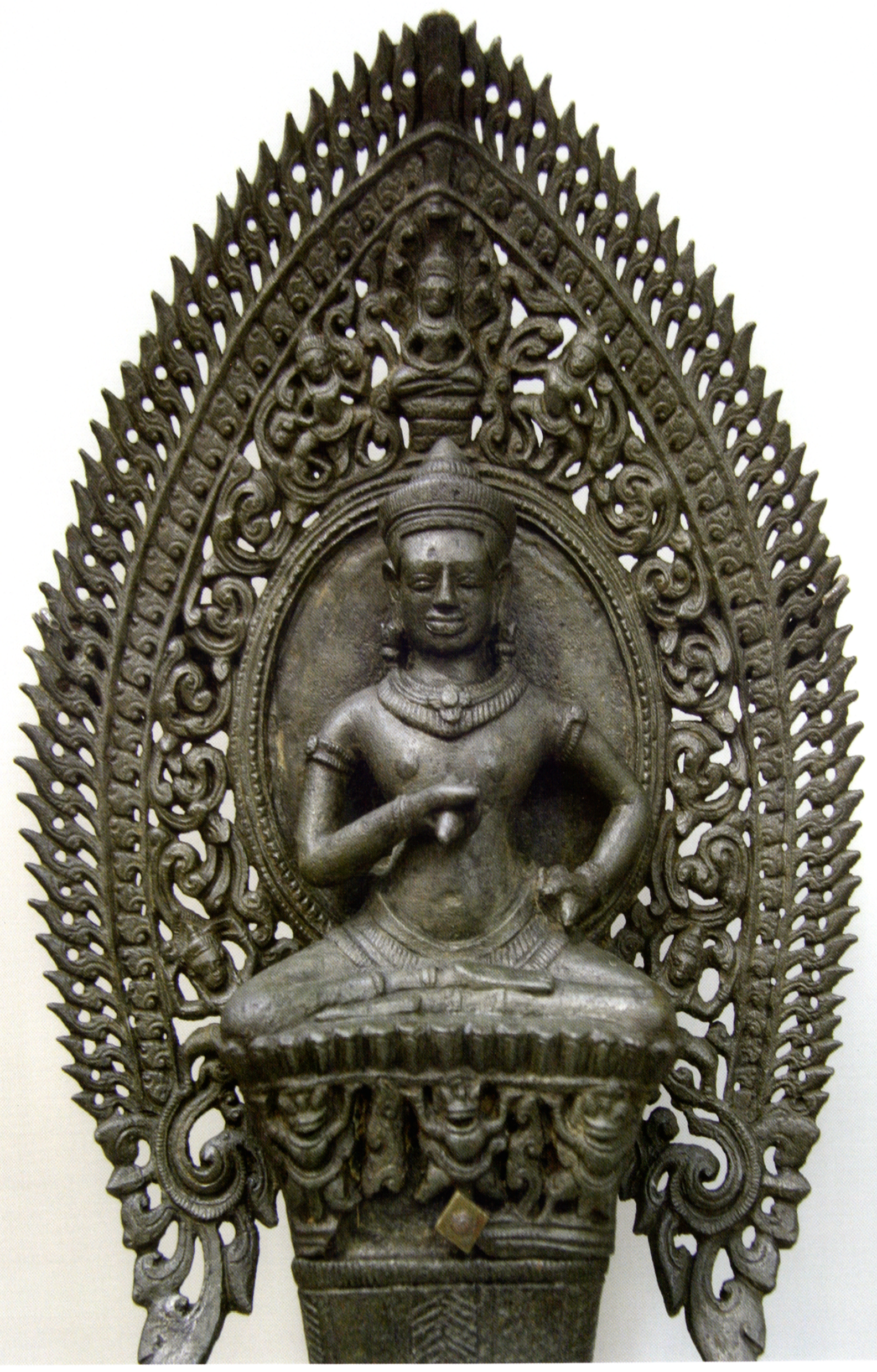




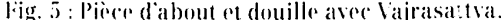
Provenanere inconnue. xil" siocle. Bromze. $11.42 \mathrm{~cm}$. muscer national de Bangkok (1.B.386).

(photo : Brice Viscest).
Autres exemples : reconstitution d'une série d'abouts d'iconographie tantrique

Notre objet ne constitue pas une pièce isolée et d'autres abouts de même type. avec about, douille et chevet, et certainement de même usage, sont connus. Eux aussi semblent s'inserire dans le cadre de croyances et de pratiques rituelles propres au bouddhisme tantrique. Jean Boisselier ${ }^{33}$ a proposé de dater certaines de ces pieces du style du Bayon (ca. 1180-1230), or la plupart d'entre elles seraient davantage à rattacher non seulement au style mais aussi à la periode d'Angkor Vat (ca. 1100-1175)

Une première sćrie d'abouts portent. à l'instar de notre pièce, uno image do Vajrasattva. Deux d'entre eux sont identiques et forment une paire. Ils ont étó découverts ensemble dans la province de Prey Veng, mais se répartissent aujourd'hui entre les collections du MNC: (ga 5420) et du musée d'Histoire du Vietnam de Hô Chi Minh-Ville (BTISS 648) ${ }^{35}$. Dans les deux cas. leur douille a disparu. mais ils ont conserve leur chevet (fig. 4a-b). Un autre about très proche mais complet. issu de l'ancienne collection de S.A.S. le prince Piyaphakdeenath. est conservó au musée national de Bangkok (I.B.386 ; fig. 5) $)^{36}$. Ces trois pièces se carac-

33. BoIssiatilik 1966, p. 340.

34. Comme le rappelait en effet. Albert le Bonheur a propos des bronzes des styles d Angkor Vat du Bayon. il convient de e dissocier style e: chronologie. Ir stvie pouvant cotre continuc ou repris très postérieurement à sa phase d'épanouissement " (1972. p. 129, n. 4). 35. Labout conserve à Phnom Penh a cité plusieurs lois publie (BBIF!) 42 |1942|. p. 212 : (itTraU 1965.

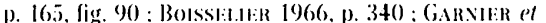

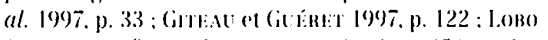
1997 . p. 73. fig. 2 : DAlsmismen 2001. p. 250, noticer 11" 1.34 : I.0130 2006) p. 169. fis. 1), alor's que celui de llo Chi Minh-Ville est inedde. Cost pourtant dans l'inventaire geméral des collections du musié d'Histoire du Virnam. ancien musée Blanehard de la Brosse, quiest donnée la provenanee de cess deux piéces : elles ont réti trouveres lors des travaux daménagement du lat lla. alors situri dans la province do Kandal. arant d'êtrer sendues à Phomom Penh à la fin des annérs 1930.

36. (“est à cet about, tries souvent publie dans le's ourrages géneraux et les ratalogues consacres a latrt llaï. que (jeorge Cordes prêtait la fonction de "porte-ciorges " lef. supra n. 28). I: noutre. comme lo rappelle déja cer aluteur. alucuse prosenancer niest connue pour erter piece - ce que confirment les archives du musée national do Bangkek -, ot il paraît done difficile de suivere Peter Sharrock lorscua il l'inclut atu sein d'un ensemble de bronzes térisent par une riche iconographie. Sur chacune delles, le trône en forme de lotus sur lequel est assis Vajrasattva présente un décor ajouré avec des lions atlantes. Leur chevet, également ajouré, est orné à ses extrémités de deux personnages féminins en attitude de danse et présente en son centre un cercle entouré par une auréole avec, à son sommet, une figure miniature de Buddha assis en méditation (samādhi). Sur les abouts de Phnom Penh et de Hô Chi MinhVille (ga 5420 et B'TLS 648). co Buddha est représenté sur une sorte de trône, entouré de deux personnages féminins en buste avec les mains en anjali. Sur colui de Bangkok (LB.386), il apparaît, en revanche, protégé par le nāga, avec également deux personnages féminins de part et d'autre - encore en attitude de danse.

En se fondant sur la définition de Vajrasattva proposée par A. Foucher (cf. supra p. 136), George Coedes identifia le Buddha miniature de l'about de Bangkok au « Buddha primordial », dont l'image de Vajrasattva représentée en-dessous aurait cété l'« émanation $»^{37}$. Il n'est pas impossible, en effet, que ce type de représentation témoigne pour le xir" siècle-date proposée pour cet about, rappelons-le - d'une évolution de la position de Vajrasattva au sein du bouddhisme tantrique khmer : de Buddha suprême ou sixième jina, il serait devenu, pour reprendre $A$. Foucher, une « portion» ou une " ćmanation » du Buddha suprême. Toujours au XII" siècle, le Buddha suprême aurait été, quant à lui, figuré sous la forme du Buddha protégé par le nāga ; une telle image cultuelle, très certainement la plus importante du bouddhisme khmer à cette époque, n'est plus seulement une évocation d'un épisode de la vie du Buddha historique Śăkyamuni, mais constitue, au contraire. une manifestation de sa nature de divinité suprême, " puissance cosmique première

prowenant de la region de Phimai. dans le nord-est do la Thailande : " From the Phimai area, bronere icons have been found of the Tantrie deities llevajra and his Yoginis. Trailokyavijayal. Prajñapauramita lwith 20 armsl and. for the first lime in 300 yeears,

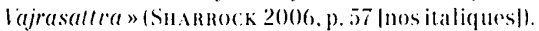
37. Cants 1923. p. 38 .

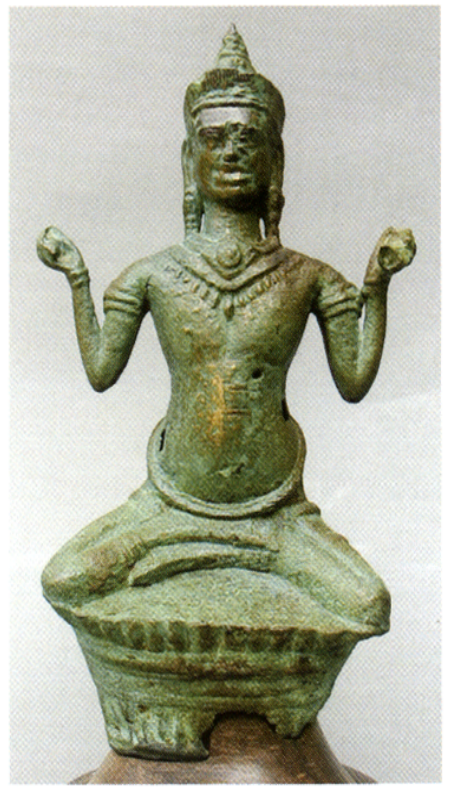

l:ig. 6 : Pièce d'about avee divinité bouddhicque masculine (?). Kor Idistrict de Thong Khmum. province de Kompong (ham). xis" siècle. Bronze. $11.20 \mathrm{~cm}$. MNC (qa 5423), (photo: MNC).

et indivisée dont tous les Buddha et les Bodhisattva tirent leur origine $»^{3 \mathrm{~s}}$

Deux autres abouts sans douille ni chevet sajoutent à cette série, même si les images qu'ils portent, certes toujours associées au bouddhisme tantrique, soulèvent des questions d'ordre iconographique qui empêchent de les identifier avec certitude. Ils sont tous deux inédits et demandent, pour cette raison, un développement spécifique.

Très certainement plus tardif que les autres abouts (cf. infra n. 82), le premier d'entre eux a été découvert dans la province de Kompong Cham - tout comme lobjet

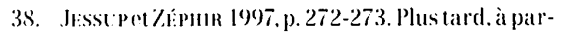
tir de l'époceue du Bayon, le Buddha protégé par Io nàga est plus spécifiquement intégre au seein de mandala lantriquess, où une place majeure lui est réscrvere au sommen de la composition. De tedles representations ne somt conmues que par quelgues moules en bronze "t par des images moulés en terre ruite et roll métal mis all jour aussi bien au (ambodge quion Thaillande

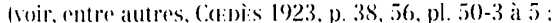

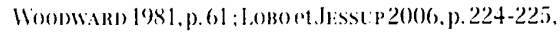
notices 1199 et 100 : Woomward 2010, p. 63.70. lig. 281. 
étudié-, avant dintégrer les collections du MNC: (ga 542.3 : fig. 6). Il représente une divinité masculine dotée toujours des deux mêmes attributs, soit le reijra et la clochette. mais dont les bras sont pliés et les mains élevées au niveau des ćpaules, un geste à notre connaissance sans autre équivalent dans l'art bouddhique khmer. S"agit-il d'un autre type de représentation de Vajrasattva?

Issu de la même collection princière que celui de Bangkok, le second about est aujourd'hui conservé au musée national de Ratchaburi (350.2533 ; fig. 7). ('et objet est, lui aussi, sans contexte archéologique. Il se distingue par une iconographie plus complexe, puisqu'il figure une divinité clairement féminine, à cinq têtes réparties sur deux niveaux $(4+1)$ et quatre bras. Ie re ejre et la clochette se retrouvent dans les mains inférieures mais sont, cette fois-ci, posés sur les hanches. Quant aux attributs des mains superieures, ils sont plus difficilement reconnaissables, même si une roue (cakra) semble se détacher de la main superieure droite. Enfin. la divinité est. elle aussi, assise sur un trône en forme de lotus au décor ajouré, avec un garude atlante au centre et deux lions dans la même attitude aux angles. Quelques éléments de comparaison peuvent être avancés afin d'essayer de rattacher certains de ces traits iconographiques à des divinités spécificues du bouddhisme tantrique attestées à lépoque angkorienne. Ainsi cette forme à quatre bras, avec le vajra et la clochette tenus par les mains inférieures. se retrouve dans les premieres images de Vaj̣apāni. Il saguit toutefois de representations masculines où le dieu. debout et en attitude de danse, est figurre avec une seule tête sous un aspect terrible ${ }^{3 "}$.

39. Au moins deux exemples sont commus : on les observe sur des stives bouddhigjues oi Vijmapini

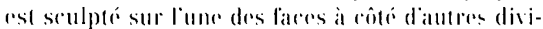
nitris. Dater da dernier quale du $x^{\circ}$ ou du debut

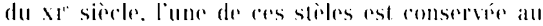

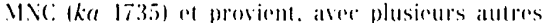
stides contemperaines. du Planom srok llisol 1925. p. 252-25t : 1.0130 ar J1 sset p 2006. p. 1+6-147.

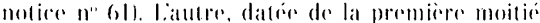
du $x^{\prime \prime}$ siecle - a moins quiclle ne soit plus lardive - se lrouve all muser naltional de Bangkok. Sal provenanere exarte est incomone mais rlle pourrait etre originaire de la provinere thaiblandatise de Prachinburilloomwan 2007, p. $77-78$. lig. $4-6)$.

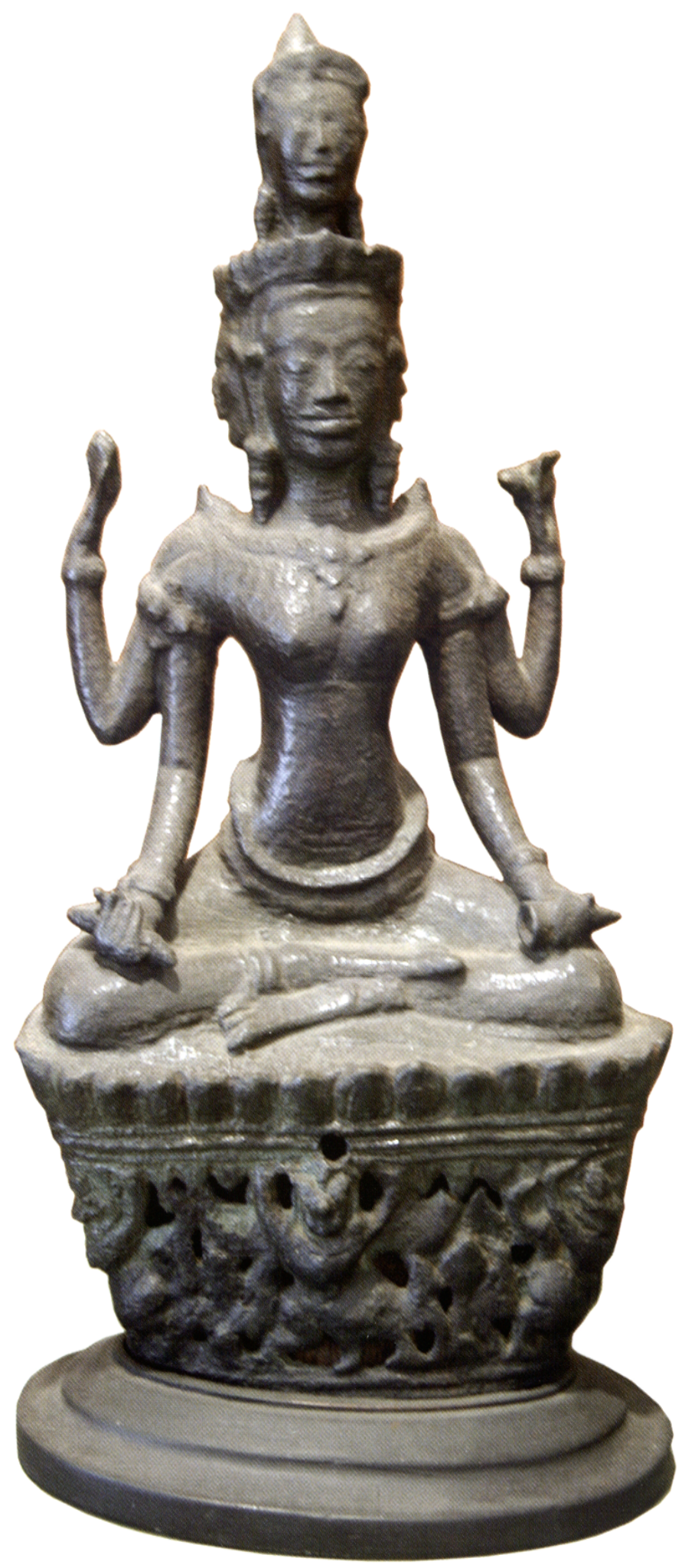

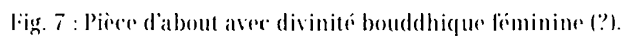

Prosenance inconnue, xal siecle. Bronze, H. 25.5 cm.

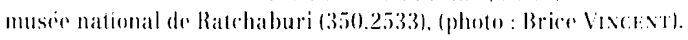


De la même manière, la roue so reconnât sur d'autres images de Vajrapāni des $\mathrm{x}^{*}-\mathrm{xI}^{*}$ siècles, quelles aient quatre ou six bras ${ }^{+0}$. les cinq têtes que porte la divinité féminine rappellent, en revanche, les premières représentations de la Prajñāpāramitāà cing têtes et dix bras, elles aussi du $x^{\prime \prime}$ siècle, qui ont été interprétées comme une possible évocation des cinq Buddha transcendants $(j i n a)^{4+1}$. Malgré cette série de parallèles intéressants - certes avec des images plus anciennes -, la combinaison des traits iconographiques présentés par labout de Ratchaburi, à dater du xir" sieccle, rappelons-le, reste inédite $\grave{A}$ notre comnaissance, aucune donnée épigraphique ni aucun texte iconographique ne viennent à l'appui d'une identification de limage divine quili porte.

Pour compléter la série ici mise en parallèle avec l'objet étudié. il faut y inclure deux paires d'abouts, toujours du même type que celui-ci mais portant une image du Buddha paré protégé par le nāgat2.

40. Il faut citer. en particulier, deux stioles bouddhiques. liune. qui est aujourdloui expessée au

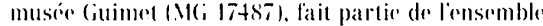
de stides decourert au Phonom Srok. I:lle montre, sur l'unr de ses faces. Vajrapäni fou peut-être Vajrin. une representation précoce d'Ilevaja lof'. supre n. 19) atvere trois tîtes of six bras, mais seuls quatre attributs sont dairement identifiables : a gauche. de bas en hatt, le rajra, lópée ro la roue a a drojte dans la main inférecure, la clochette (Jisste et \%iplut

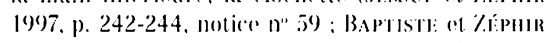

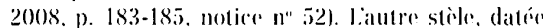
du $\mathrm{Xl}^{2}$ siecte et anciennement conservée au musée du Vat Po Vial à Battambang lancien n" ins: 317ı, a malheureusement disparu el seules des photographies d'archives permetent aujourd'hui de lietudier. l:lle figure un Vajapañ (?) à quatro bras : ses mains inferieures sont revisces sur la poitrine et porten chacune un rajra, alors que ses maias superieneres droite et gauche tiemont respertivement une rour

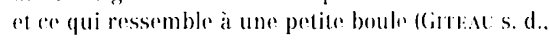
p. 8.5. notice $1 " 317$ : 1.0830 2006, lig. 41 .

4. Cente hypothese a rete. notamment. formu-

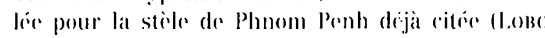
af Jisste 2006, p. 1461. Dautres images de la Prajñaparamita a cing têtes ed dix bras sont ligurees sur trois steles plus ou moins contemporaines relle de Bangkok : une atutre stole da Phnom sook qui a ctre publiée seulement par louis linot 11925 p. 2.53, n. 1, pl. 2.5) : enfin, une stive incedite. elle atussi originaiere du Phonom Srok et atujourdhui conservere a1! musere prowincial do Batlambang (ka 00) 58 ). Si.

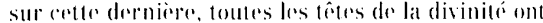
fre malheureusement mutileses a une date recente. relle-ci reste néanmoins clairememt identifiable.

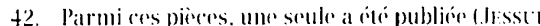

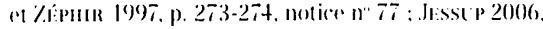

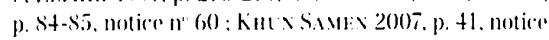
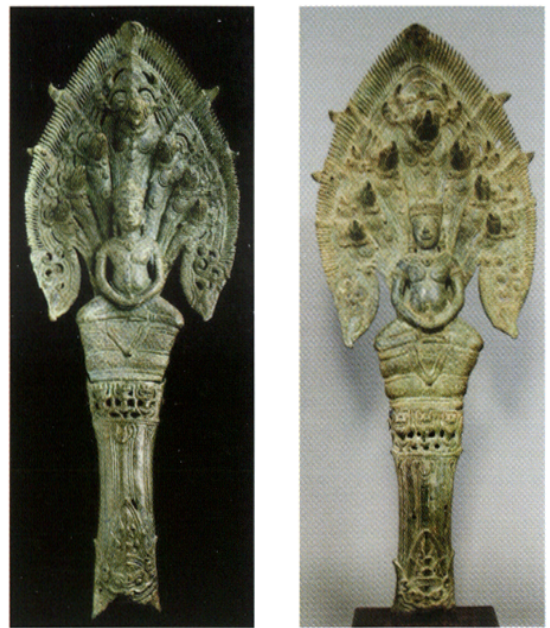

Fïg : 8a-b. Paire de pières d'about arece Buddha parri protegre par lo näga.

"Banteai (hha " (village de " Kos l'rag". district de prey (hhor ou Srei Santhor [?] province de Kompong (ham). xir sievele. Bronze. H. 49,5 coll. MVC: (ga 5.5931 " Angkor National Museum, Siem Rrap (ya 4057). (pholes: MNC).

Provenant de la province de Kompong Cham - comme notre piece -, ces quatre abouts seraient encore à attribuer au style et à la période d’Angkor Vat. lïconographie de ces derniers abouts, tout comme leur parenté stylistique avec ceux décrits plus haut, invitent à penser qu'ils ont partagé une même fonction au sein de rituels propres au bouddhisme tantrique. Ie fait qu'ils ont été retrouvés par paires - tout comme les deux premiers abouts présentés (ga 5420) et BTls 648) - semble en outre indiquer que plusieurs enseignes bouddhiques identiques pouvaient être portées dans le cadre des processions ${ }^{43}$.

Des pavois pour divinités bouddhiques

$\grave{\Lambda}$ côté de cette première série dobjets, existent des abouts d'un type plus complexe, composés à la fois d'éléments

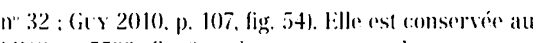
IIXC: ege 5593 : fige. Sal. alors que som pendant se troure aujourd hui a l': nngkor National Museum de Sïm Rrap

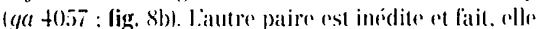

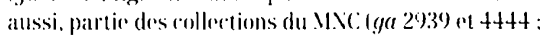
fig. 9it-b). lintin. ce's mêmes collections possident un autre about identique aux deux premiers. mais malheureusement non documente lga 5220.1-21.

4.3 Dams la notice quili at recemment consacrés a

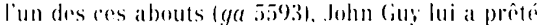
une fonction similaire déplement denseigne, même si. selon cel atuleur. il aturate ragalement pu servir a derorer une " chaire à prôther" enresching platform) ou encore un palanguin destini à porter une image de culte $(6)$ y 2010, p. 107$)$. décoratifs et de statuettes, qui répondaient sans doute à un usage distinct. liux aussi utilises dans le cadre de rituels qui seraient propres au bouddhisme. tantrique ${ }^{t 4}$, ils auraient constitue les éléments centraux de pavois toujours employés dans le cadre de processions. Ces derniers permettent donc de compléter notre aperçu de certaines des pratiques rituelles qui se seraient développées au sein de ce courant du bouddhisme à l'époque angkorienne.

Un exemple particulièrement intéressant est fourni par un ensemble presque complet de pieces en bronze qui semblent avoir formé la décoration de deux pavois. Il a été découvert de manière fortuite dans lancienne plantation de Christianville, situé à une trentaine de kilomètres au nord de Kompong Thom, avant d'entrer dans la collection de son propriétaire, Georges Colin. Malheureusement, l'incendie de cette plantation en a détruit une partie et seuls quelques fragments ont pu rejoindre le MNC à la fin des années quarante. Certains ont toutefois été publiés et l'ensemble original est aussi connu par plusieurs photographies d'archives ${ }^{45}$. Jean Boisselierth a propose de le dater du style du Bayon, mais, là encore, il serait à dater du style et de la période d’Angkor Vat.

Cet ensemble était à l'origine constituó de deux jeux de pièces en bronzo plus ou moins identiques. Chacun comprenait un grand motif central, lui-même constitué

44. Bolsstilit: 1966, p. 332

45. Lensemble de Christianville nest en réalite mentionmi que dans quelques publications (GITlAs 1961, p. 222, 226 : (iTlAal: 196.5, p. 140)141. (ig. 79-80 : Bosssti.tl: 1966, p. 332. pl. 58-1:

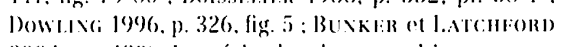
2004. p. 420). la sirie de photographies conserveres à la photothégue de lelitio permet toutelois d'identifier les differents fragments qui se trousent atujourd'hui au MAC llonds Cambodge, raf. (:I.1) 1201t a 12018). du nombre de seize. ces derniers comprennent : un personnage masculin assis lgat 36311 : deux personmages féminins dansant ya 3604 at 3605) : un gerude lga 3611$)$ : trois l'agments dar-

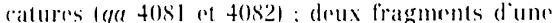
triade vishonoute lya 3597 of +0.86$)$ : ansi que sept fragmonts indistincts lya $3162,3163,4115,4116$. $+130,+131$ (1 +1321.

46. Bolssit.tin 1966, p. 332 

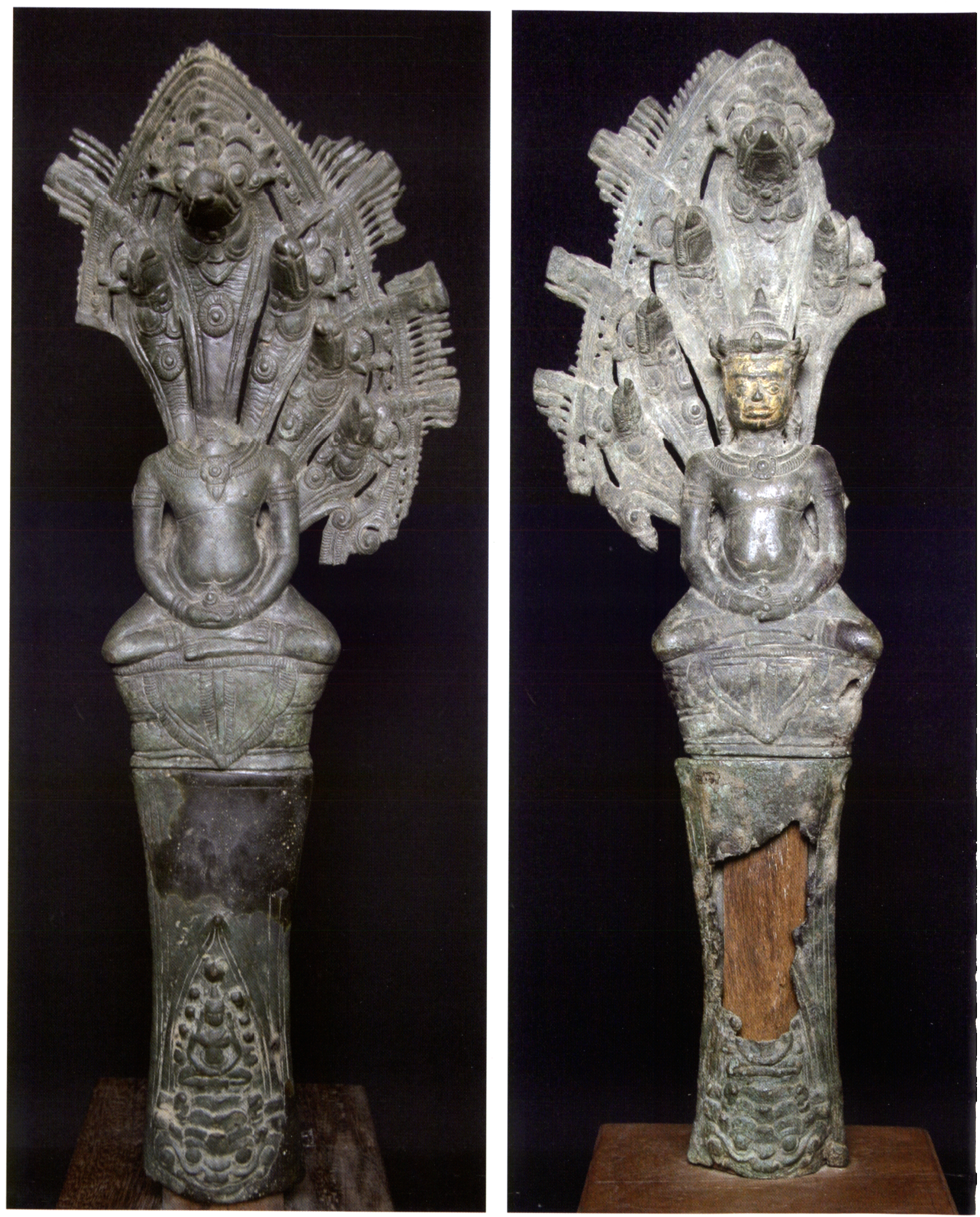


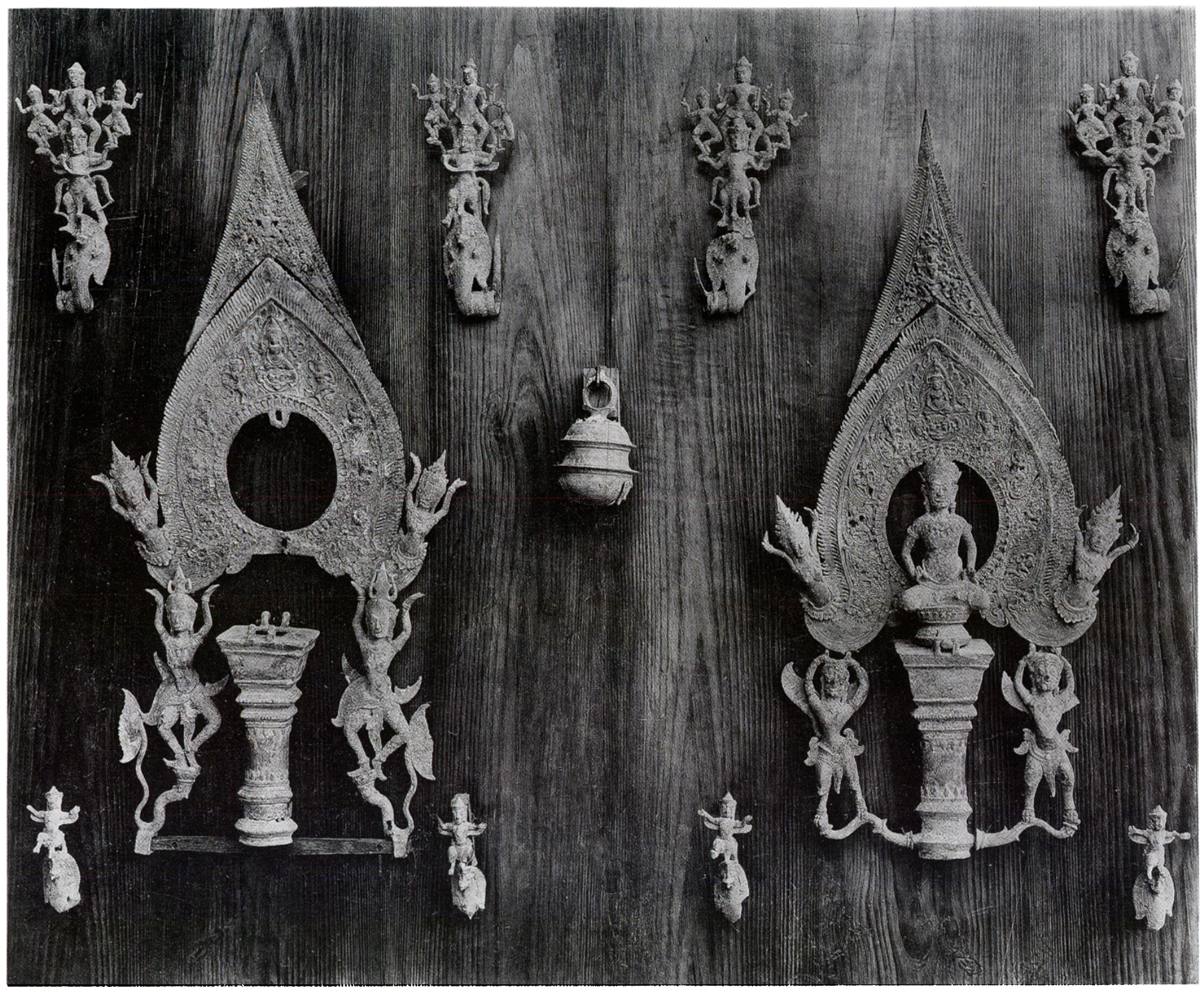

Fig. 10 : linsemble de (hristianville. Rígion de Kompong Thom (provinee de Kompong Thom) xar" siecte. Bronze, (photo : Ícole francaise d'fixtreme-0rient, lionds Cambodge, ref. CAM 120141

Lïs. 9a-b : Paire de pioces dabout aver Buddha pare protege

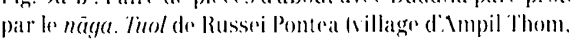
district de Pres (hhor, province do kompong (ham

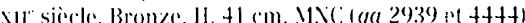
tphotos: Brice Viscente de plusieurs éléments assemblés, ainsi que des ornements d'about plus petits. laccrochage ancien de ces pièces, qui apparaît sur une photographie d'archive, permet de se faire une idée de l'aspect général que devaient avoir les pavois qu’ils decoraient : seules manquent en réalité les armatures en bois qui reliaient chacun de ces éléments (fig. 10).

les grands motifs centraux rappellent par la composition de leur décor certains abouts de la série précédente (ga 5420 ), B'TI.S 648 et I.B.386). De même, la divinité centrale est encadrée d’un chevet. certes plus ćlaboré, mais de même forme générale et ajouré de motil's décoratifs similaires. Leur iconographie est aussi clairement bouddhique ${ }^{47}$. Ainsi se retrouve au sommet de l'auréole la figure miniature du Buddha suprême assis en samädhi, mais cette fois-ci sur une tête de käla. Un personnage féminin est également figuré à chacune des extrémités du chevet, mais en buste et les bras levés. alors que sur l'un des deux grands motif's,

47. I.es pieres dabout sont, en revanche, ornoes de garuda et de triades vishnouites montiós sur des garuda, qui chevauchent rux-momes des naga. Peutotre res représentations nótaient-elles que devoritives. à l'exemple des garuda atlantes qui supportent l'un de's deux grands motifs - à moins quiun lien n'ait existe entre ces figures de garuda ot les images prinripales porties parles deux grands motifs. 


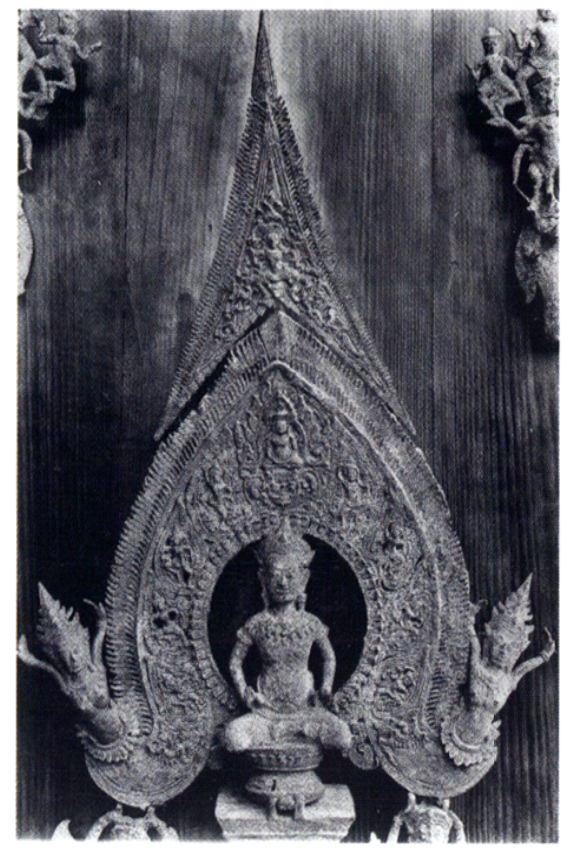

lïg. 11 : Détail d'un des grands motil's en bronze. tphoto : École françase d'lixtrême-()rient. Fonds Cambodge, ríf (CAN 12017).

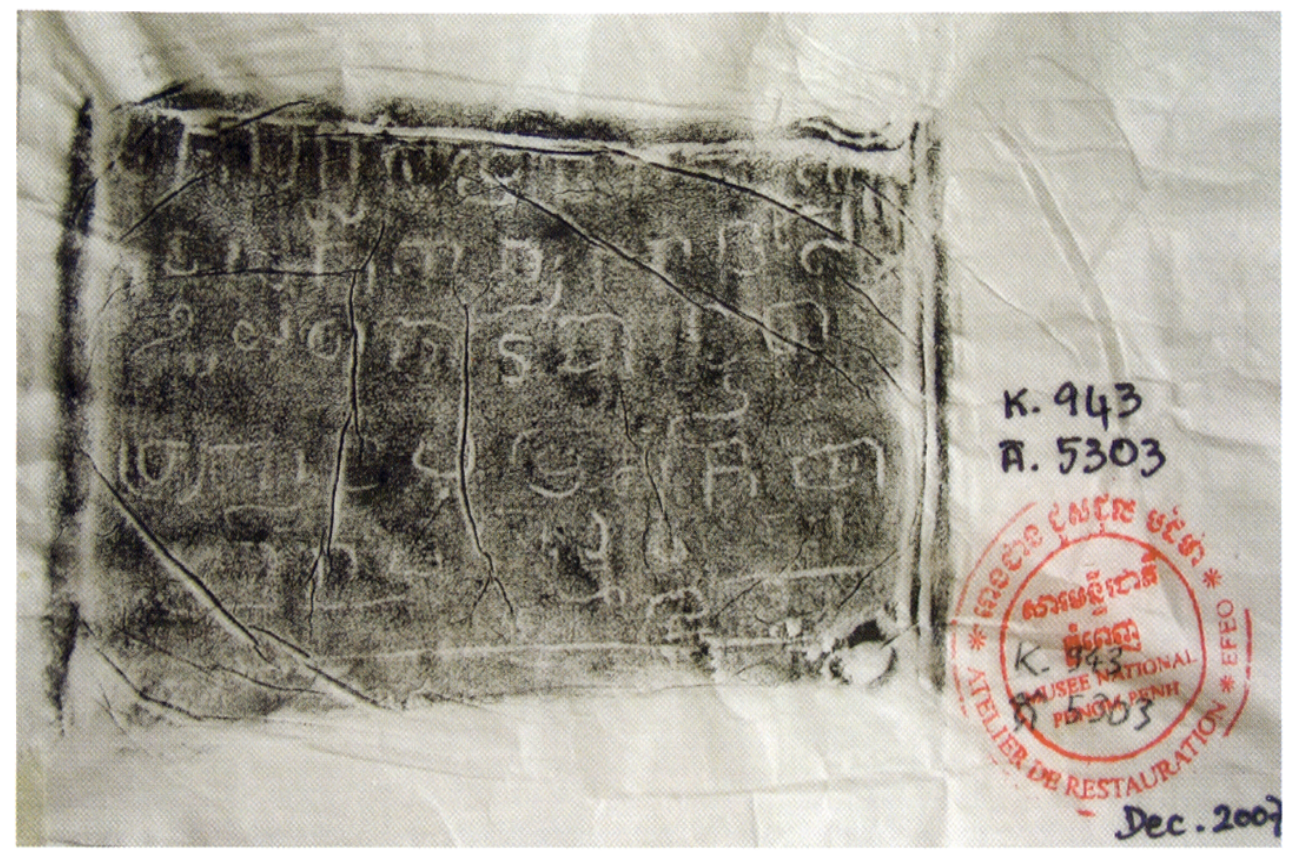

lïg. 12: listampage de l'inscription K. 943.

(phote: : Atelier de conservation-restauration de seulpture, MN( deux personnages féminins en attitude de danse soutiennent ce dernier. Cependant, de nouveaux themes iconographiques, toujours bouddhiques, viennent enrichir le décor. Huit personnages fóminins dansants, très certainement identifiables en raison de leur attitude comme des yogini - sans que celles-ci soient pour autant individualisées par un quelconque attribut -, sont ainsi répartis sur lo pourtour de l'auréole, de part et dautre du Buddha suprêmet+s. Un autre personnage féminin dansant, avec cette fois-ci les jambes écartées et les mains au niveau de la taille, est en outre représenté sur la pièce de couronnement du chevet. linfin, des deux images principales portées par ces grands motils, une seule a été conservée : il s'agit d'un personnage masculin paré assis sur un trône rond en forme de lotus quil semble possible didentifier comme un Buddha,

48. Sans doute estere re thome iromographique particulier qui latisait ereriere à Jean Boisselier quer par leur deror. or type dabouts - quil qualifie d'u consembles romplexes" - crocguaient " plus of moins directement certaines compesitions ligureses sur les Prih Patima limages mouleses on terre cuite.

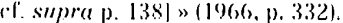

soit le Buddha suprême, soit l'un des cinq Buddha transcendants ou jina (fig. 11). Ses deux mains légèrement appuyées sur les cuisses ont, en effet, chacune le? pouce et l'index joints, réalisant ainsi le: geste de l'argumentation (vilarkamudrā). limprunté à l’art de lovāravatī, le geste du double vitarkamudrā apparaît pour la première fois dans l'art khmer au temple. de Phimai, soit à partir du début du XII" siecle, sur un linteau où figure une frise de Buddha debouts parés ${ }^{+1}$. Sans doute cette représentation laisait-elle partie à l'origine du programme iconographique de ce sanctuaire, fortement influencé par le bouddhisme tantrique. Avec: la divinité de l'ensemble de Christianville, un nouvel exemple dassociation de ce type de représentation avec le bouddhisme: tantrique serait donc désormais attesté à l'époque angkorienne et en dehors do Phimai.jo.

49. Botsste.ti:n 1966, p. 264-26.5. 274, lig. 6.50 (60 linteau est aujourd hui conservi au musere national de Phimai.

50. Outre lensemble de Christianville, dautes lragments faisatut partie dabouts similaires, à plusieurs cáments, sont comnus, même sils restent pour lessienticl conservis au sein de rollertions privines.
Ces nombreux paralleles suggerent que notre about s'inscrit dans une série d'objets rituels en bronze qui auraient constitué les éléments de divers supports enseignes et pavois - pour images divines. la plupart dateraient du xil" siècle, avec aussi quelques exemples plus tardifs, et

Ainsi en est-il d'un about, portant une figure identifiée comme crlle d'un Vajrapāini (?). daté de la fir

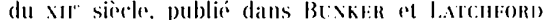
2004 (p. 420-421, notice n" 1511. I.es tonons visibles sur les faces antririeure ot pesterieure du crome. lui-même indépendant de la divinite. indiqueraient

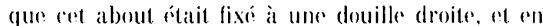
feraient done un about du meme type que creux de christianville - celte comparaison avatit ré deji proposée par les deux auteurs. Il faut citer. en outre. un fragment dabout, lui aussi sans doute à dater du xul sièrle, qui est aujourd hui conservo au Vuseum

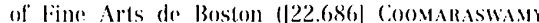
1924-1926, p. 237, pl. 22 : Borssilla:k 1966, p. 332 : Anonyme 1982. p. 198-199, notice n" 188 : lowerts "t al. 1992. p. 193. motice n" 185). Il figure sous une arcature un personnage féminin dansant aver les deux bras levés. qui rappelle ceux commus par l'ensemble de Christianville. Infin, deux chesets tries proches de crux alppartenant à ce meme ensemble

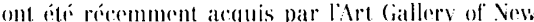
South Wales de Sydney (232.200(0) net le Norton Simon

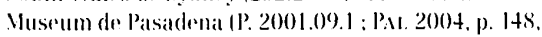
notier n" 110). Tous deux sont quasiment identiques. aver la disinitó llevajra représentere all sommet do latureole, ses huil yogimi réparties sur son pourtour el deux autres persomnages fíminins dansant aux ixtrémitós. 


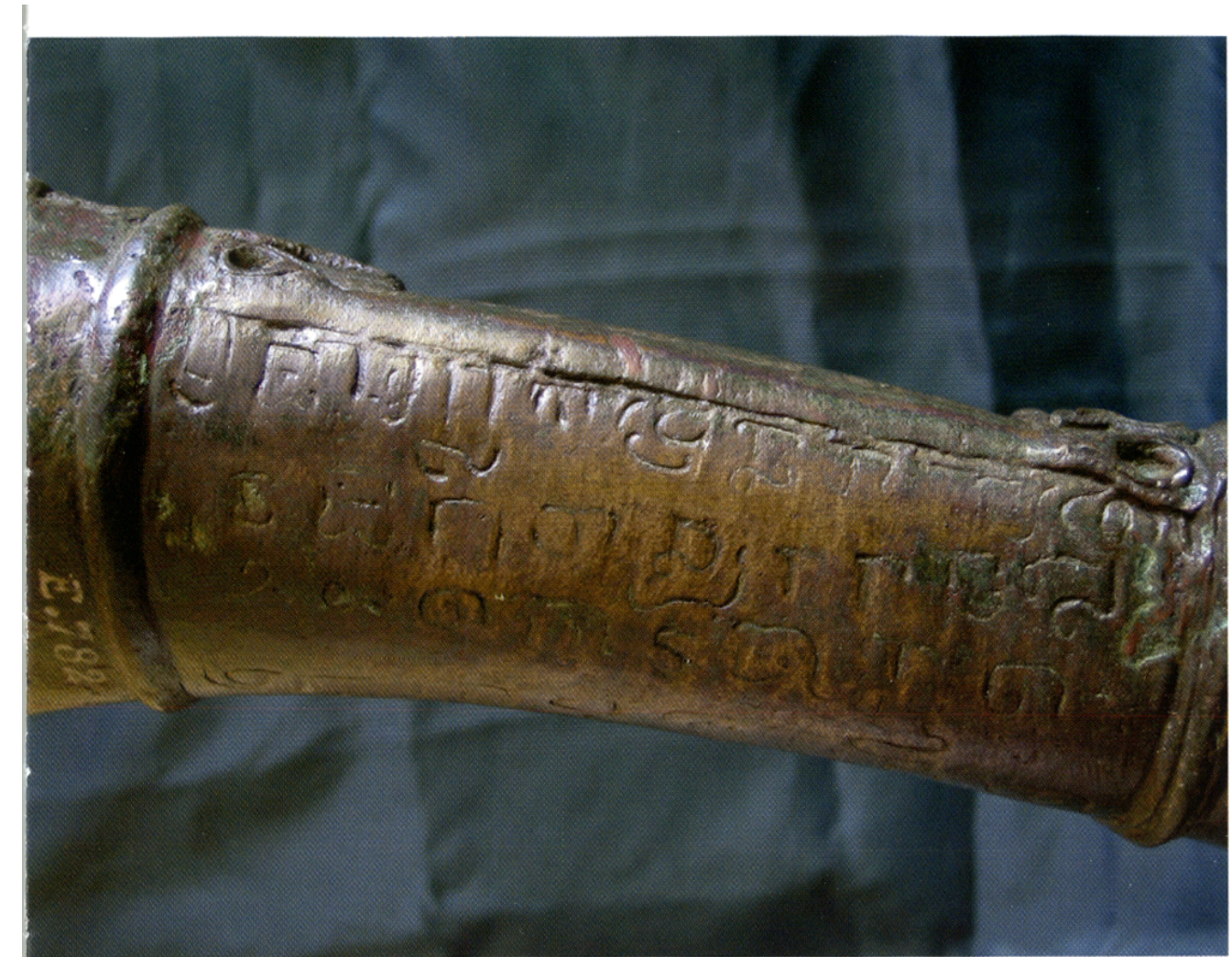

Fig. 13 : I.ignes 1-3 de l'inscription K. 943.

iphoto: Atelier de conservation-restauration de sculpture. MN(:).

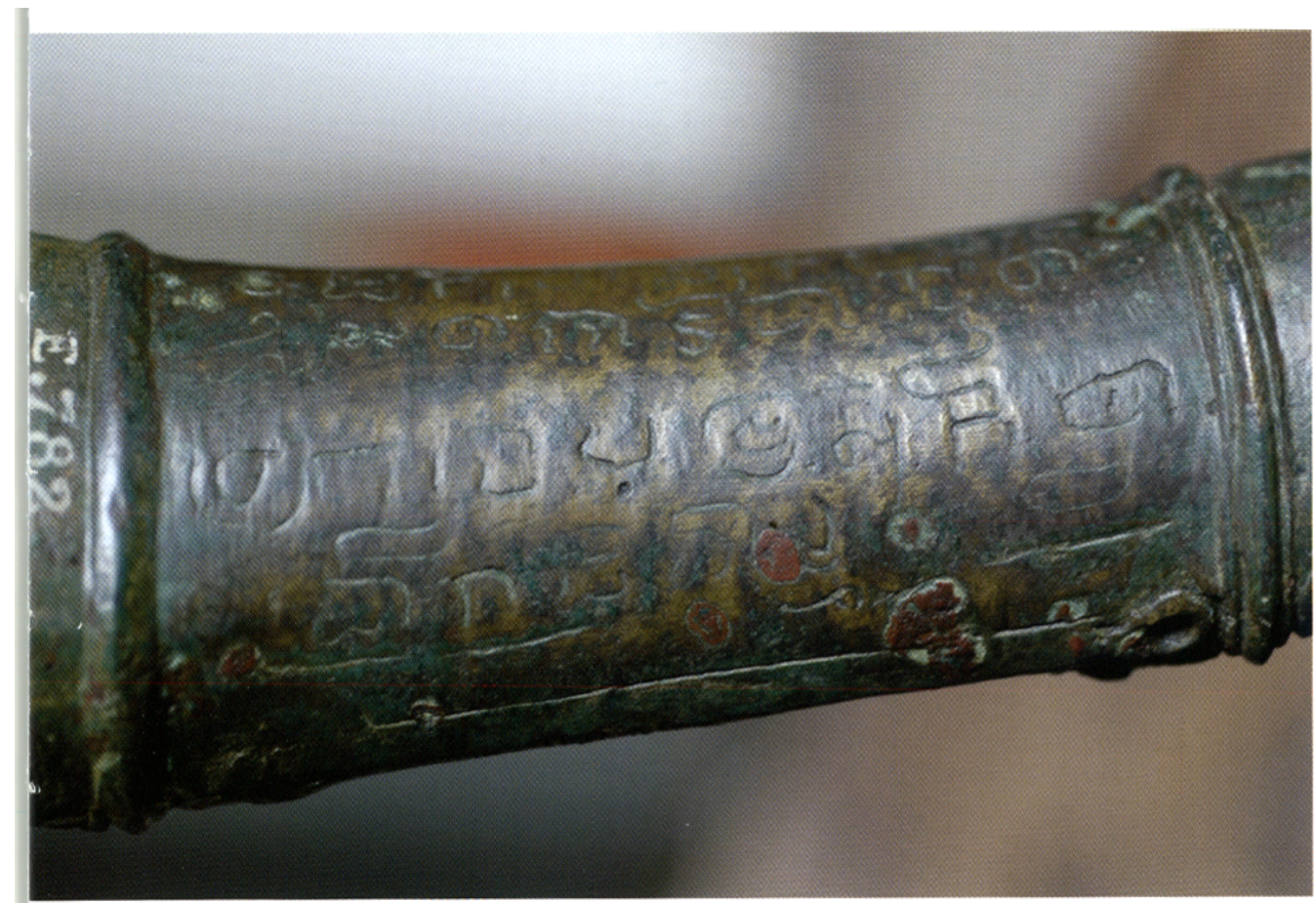

Fig. 14: I.ignes 4-5 de linseription K. 943. (photo : Erie Boterooxivalt offriraient ainsi un nouveau témoignage de l'importance du bouddhisme tantrique à cette époque, alors même que celui-ci connaît une dernière phase de mutation. Selon nous, tous ces supports étaient destinés à être portés dans le cadre de processions bouddhiques. Une illustration plus ou moins contemporaine et, à notre connaissance, unique de ce type de pratique rituelle s'observe sur un des linteaux du temple de Phimai : sur celui-ci est figurée une image, très certainement en bronze, d'un Buddha assis en samādhi portée sur un pavoi, avec plusieurs officiants et un orchestre qui le précedent, alors qu'un éléphant ferme le cortegen." Au sein de cet ensemble reconstitué d'objets rituels, dont certains fonctionnaient vaaisemblablement par paire, notre about constitue une pièce unique, ce dont témoignent à la fois le soin particulier apporté à sa réalisation et le contenu de linscription quil porte.

\section{L'inscription K. $943^{52}$}

\section{Édition et premiers éléments d'analyse}

L.inscription se compose de cinq lignes en vieux khmer de sept ou huit caracteres chacune ${ }^{33}$. Lestampage de celle-ci (fig. 12) est moins lisible que les photographies (fig. 13 et 14) et deux passages restent particulièrement difficiles à déchiffrer, dautant que la surface de la douille, largement patincé présente quelques traces de corrosion. Son écriture est irrégulière avec des caractères de forme plus ou moins carrée. Lexamen au microscope optique des diverses parties inscrites révele, en outre, des traits plus ou moins profonds gravés en plusieurs fois, ainsi que de nombreux

51. Ro(1:10.1 2005. p. +72. (ig. 10.953.

22. Vous souhatitons remercier ici. pour nous avoir aimablement procure des photographies de linscrip-

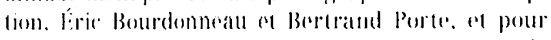
leur concours quant a la traduction en a la lecture de linseription. Philip N. Jenner en Dominique Soutif

53. Ln raratelere ou une marque a rée également inserit sur liabout. au niveau de la face posterienere du trone de la divinité. 
arrachements en surface. Ces dernieres observations indiquent clairement que linscription a été directement gravée sur le métal, après la fonte de la douille. ce qui paraît étonnant au vu de la longueur du texte et de la forme convexe du support. Il semble toutefois difficile d’imaginer quelle ait été inscrite longtemps après que la douille et l'about ont été réalisés.

Il convient de noter qu'il n'y a apparemment aucun viräma dans linscription ; la transcription que nous proposons les restitue afin de faciliter la lecture. Par ailleurs, ce texte présente des formes inhabituelles qui rendent sa traduction délicate. Les hypothèses que nous proposons ne prétendent pas être conclusives. Texte:

lÉdition fondée sur l'examen de l'estampage EII:O AMPP 5855, et des photographies AMPP 148:5-1498: J. Estèvel

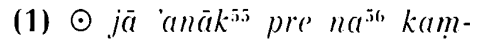
|m|rale(2)n jagal chpar ranase

(3) oy la l'à) ralpländalasia (4)

tra(lya)ri pamre mu gi (lh)là(s)(y)

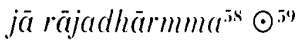

\section{Traduction :}

Il comvienl que lees gens qui serevent ${ }^{(1)}$ auprès du Kampraten Jagat

34. I in autre estampago est conserve a la Biblioshònue nationale de liance sous le mumero 1168 (9) a : voir $/$ VIII. p. 217 .

5i. 1) nombreuses formes de nak, "person. indi-

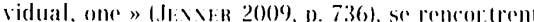
dans les inscriptions. Si 'anak a näk se trousent do

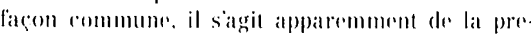
miere ocerurrenere de la lorme 'uncik.

56. Corrigare on $n \bar{a}$.

57. Cotto forme est un hapas derorespond at un anthro-

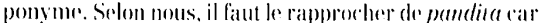
memes il est rare do voir une erreur daus les voyelles do reterme satnsk rit sousent utilisí dans les inseriptions a

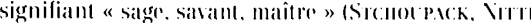
ot Rivol: 1987. p. 399). il est rourant que les consonmes rétroflexes soient remplateres par les dentales.

58. Corrigore rom rajadharma.

59. Ies deux signes de ponctuation présentem ied des lormes difliónentes.

60. Pre est une forme verbalde at nous lui domneans de sens do "servir". Il a touteleis plusieurs sens « 1 To ratuse to move 1...). 2. To rause Imathel. hase (...). to alssign, appoint (.... 3. To appls. use, make use ol' emples " (Jaxver 20(39, p. 380). lne traduetion suivant le sens litleral du terone, a savoir « utiliser" sousrnendrait un complement dobjet direst non exprime (de) Chpar Ranase donnent leecil à $\bar{A}$ vapandita (de) Tralyañon qui est. serviteur ici.

Qu’il soit offert au titre de fondation royale.

D'un point de vue grammatical, linscription présente quelques particularités : le texte commence, notamment, par la forme verbale jā qui ne se trouve pas habituellement en tête ${ }^{62}$. Elle offre également des séquences et des termes bien connus. la séquence theày jā rājadharma se retrouve, par exemple, dans l'inseription K. 33 du Phnom (isor (1017-18: IC' III, p. 152), vù ce sont divers présents cesclaves, terres) qui sont « offerts à titre de fondation royale ", un type de donation leur conférant le statut de présents pérennes et exempts, entre autres, de l’impôt. Comme l'explique George Coxdes, "les merites |des fondations| étaient transférés au roi qui, en échange. accordait les exemptions demandées $»^{6.3}$.

Un autre élément méritant d'ôtre relevé est l'usage qui est lait du verbe 'oy, génera-

qui so rapportratat all support de l'inscription. Selon nous. ce sens litteral ne convient pas dans la mesure oin la traduetion de la phrase serait : " Il combient quen les gens utilisant feet objet| aupreis du Kammaten dagat de Chpar Ranase fo domnent l... m. Civla impliçuerait dome que lobjos aurate rote utilise au sein du simetuaire du

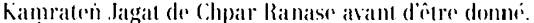
(or, comme nous lavons vu, il semble bien que lius-

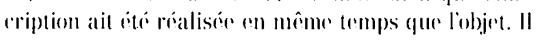
est. ell revanche, possible de sappurer sur le sens du derive de pre. pamre. signifiant "One who is alssigned or employed : servant. rimployeren (ibid.. p. 333). pour latire l'hypothese que ces gans étaiont de's serviteurs.

61. [ne atutere oreurrence du toponyme tralyeain apparaît dans l'inscription $k$. 293 provenant du Bayoun et datce du xull" sierele : il y est question d'un

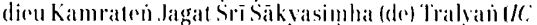
III. p. 196. I. 31. Saktatsimbat ou « le lion des Sakya" camt lun des noms du Buddha historigue, il ne lat atueun doute gue cotte atutere divinite de Tralsain appartenait au pantheon bouddhique.

62. Sclon Philip N. Jenner, jä signilie « 1. To be worth, equivalent to. the same ats: to be, serve als. 2. To be good, right, just, proper, suitable, meen, desj. rable: to be well, well-off, in good riecumstances. 3. To be worlhy or deserving of. to merit " (200).

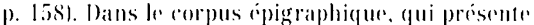

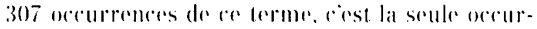

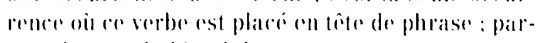
lant du serus habituel du terme, mous conjecturons lat formule impersonnelle \& il enusient que ". hypothese que mous avons rendur par des ilaliques.

6.3. K(: III, ). 1+8, n. 2. lement traduit par " donner " : les autres inscriptions sur métal du corpus utilisent. elles, le verbe juan, ou, plus exactement, son dérivatif jamnean. la différence entre ces deux verbes a déjà été mise en évidence, notamment par les recherches de Deth Thach ${ }^{\text {(4) }}$. Les deux verbes impliquent deux relations différentes entre les acteurs concernés par la donation (le donateur et le donataire) et la transaction ou tout type de transfert de propriété. L'emploi de jammean dans les autres inscriptions du corpus épigraphique s'explique ainsi par le fait quil y est question d'une offrande faite à une divinité, alors que dans le cas de la presente inscription, le don, fait à un être humain, serait spécifió par 'oy. mettant ainsi laceent sur le donataire. Ici, le donateur comme le donataire sont des personnes.

Même si la traduction proposéo est hypothétique, lo sens général du texte fournit quelques éléments sur l'histoire de l'objet lui-même et sa fonction : l'about apparaît clairement comme l'un des objets du culte d'une divinité, même si lon ne peut en dire davantage à ce stade de létude. Il reste à définir le lien existant entre la divinité qui le coilfe et lo Kampraten Jagat de Chpar Ranase dont parle le texte. Ia relation entre les deux lieux mentionnés, nu gi, « ici » (1. 4), et chpar ranase (1. 2) doit rigalement être éclairée, tout comme la raison du transfert de l'objet de l'un à l'autre b. Pácit étomant. l'objet est donné à un homme, alors que, selon l'épigraphie, tout objet de culte ou fourniture nécessaire au lonctionnement du temple est généralement donné directement à la divinité. Cet élément. montrant lestatut particulier de notre objet, permet sans doute de mieux comprendre le soin apporté au décor de l'about et surtout de la douille portant linscription.

6.t. Communicaltion personnelle. juin 2008 .

6.5. Ce nost quiune fois que mous aurons presenti

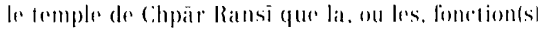

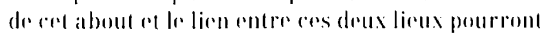
se dessiner lel. infira p. 15t).

66. On notera que celle inseription mentionme sculement une "distriet de Chpàr Ransi " "l ne lat pals refforenere a ulle diviniti. 


\begin{tabular}{|c|c|c|}
\hline INSCRIPTIONS & DATE (en śaka) & Provenance \\
\hline $\begin{array}{l}\text { K. } 682^{66} \\
\text { (CEDD̀̀s 1931, p. 15) }\end{array}$ & 842 & Prasat Thom \\
\hline $\begin{array}{l}\text { K. } 178 \\
(I C \text { VI, p. 192) }\end{array}$ & 916 & Phnom Mrech \\
\hline $\begin{array}{l}\text { K. } 158 \\
(I C \text { II, p. 97) }\end{array}$ & 928 & Tuol Prasat \\
\hline $\begin{array}{l}\text { K. } 276 \text { et K. } 277 \\
(I C \text { IV, p. } 153,155)\end{array}$ & Postérieures à 959 & Ta Kev \\
\hline $\begin{array}{l}\text { K. } 879 \\
(I C \text { V, p. 235) }\end{array}$ & 962 & Prasat Sneng \\
\hline $\begin{array}{l}\text { K. } 1158 \\
\text { (Chirapat Prapandvidya 1990, p. 11-14 ; Estève } \\
\text { 2009, p. 442-452) }\end{array}$ & 988 & Sab Bak \\
\hline $\begin{array}{l}\text { K. } 237 \\
\text { (IC VI, p. 293) }\end{array}$ & 989 & Prasat Preah Khse \\
\hline $\begin{array}{l}\text { K. } 169 \\
\text { (AYMONIER 1900, p. 452) }\end{array}$ & $\mathrm{X}^{\mathrm{e}}-\mathrm{XI}^{\mathrm{I}}$ siècle & Prasat Chikreng \\
\hline $\begin{array}{l}\text { K. } 249 \\
(I C \text { III, p. 97) }\end{array}$ & 1031 & Prasat Trau \\
\hline $\begin{array}{l}\text { K. } 254 \\
(I C \text { III, p. 180) }\end{array}$ & 1051 & Trapeang Don On \\
\hline $\begin{array}{l}\text { K. } 1219 \\
\text { (EstÈve 2009, p. } 432 \text {; SoUTIF 2009, p. 602-606) }\end{array}$ & 1089 & Inconnue \\
\hline $\begin{array}{l}\text { K. } 273 \\
\text { (CGEdÈs 1906, p. 44) }\end{array}$ & 1108 & Ta Prohm \\
\hline
\end{tabular}

\section{le temple bouddhique de (ihpär Ransì}

liexpression chpar ranase, comme désisnant le lieu de résidence d'une divinité, est connue de l'épigraphie ancienne. Je nom Chpär Ransīse retrouve, avee des variantes orthographiques (Chpar Ransi. Chpar Ransĩ, Chpār Ransi. Chpā Ransi), dans plus d'une dizaine d’inscriptions du corpus épigraphique angkorien, dont l'éventail chronologique se déploie de 842 śaka (920-921) à 1108 saka (1186-1187): (irâce à létude. qưlitienne Aymonier a menée sur l'inscription K. 169, dont il compare le texte khmer et le texte sanskrit"ī, et grâce à linscription K. 2:54, nous savons que Chpār Ransī est la traduction khmère du composé sanskrit ramśâräma, « le jardin des bambous ». Il

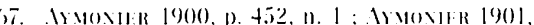

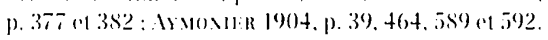

s'agit donc de l'équivalent du veluvana des

Face au grand nombre des oceurrences, une première question simpose : sagit-il, au fil des inscriptions, et done au fil des siècles. d'un seul et même temple?

J.es inscriptions K. 158 , K. 237 et K. 254 - et peut-être K. 879-ritablissent de concert l'affiliation religieuse d'un temple nommó Chpār Ransī : la divinité qui y est installée est criptions, à deux exceptions prìs, lo temple de Chpār Ransī est lić à une divinité portant le titre de « Kamraten Jagat » : kemraten jagat chpär ransī (ou sess variantes) b". ()r. les divinités nommées Kamrater Jagat (K. J.)

6.8. I partie du milien du $\mathrm{x}$ sionese la titulature disine se scinde. dans lépigraphion. on deux ratr.

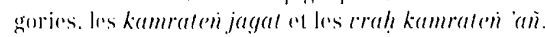

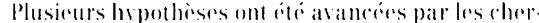

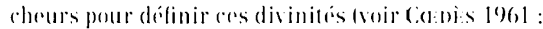
1.11.10\%10 1981: Incotes 199+1. textes bouddhiques. un Buddha. Relevons que dans toutes les ins- sont en règle gémérale spécifiées soit par un theonyme, soil par un toponyme, sans quintervienne la particule ày (« dans ») précisant qu'il s'agit d'une localitén ${ }^{(0)}$. Ainsi, dans K. 254 et K. 276, lexpression kammrateñ jagat chpā ransi doit etre traduite par « lo Kamraten Jagat de Chpãr Ransi ».

Il est ainsi remarquable qu'il n'y ait pas besoin de préciser, dans la majorité des cas, ni l'identité de la divinité concernée ni l'affiliation religieuse du temple. Dans la plupart des inscriptions (K. 276, K. 277, K. 879, K. 249, K. 254, K. 1219 et K. 943), la divinité est uniquement identifiée par la prósence dans la partie khmère de l'expression « kammralen jagal chpär ransi », sans que sa nature soit précisée plus avant : dans trois cas (K. 158, K. 1158 et K. 273), nous possédons, dans la partie sanskrite, le nom de la divinité qui nous renseigne sur sa couleur religieuse. Ainsi, il apparaît que nous n’avons pas affaire à une divinité quelconque, mais à une divinité renommée : la seule évocation du lieu de sa résidence suffisait à l’identifier.

Nous ne suivons donc pas ceorge Condes lorsquil affirme, à propos de Chpār Ransī, que u ce nom semble avoir été porté par plusieurs sanctuaires $»^{70}$. Il nous paraît, bien au contraire, qu’un seul sanctuaire était porteur du nom de Chpār Ransī. Je fait que, dans le corpus épigraphique, le K. J. de Chpār Ransī apparaisse souvent en liaison avec un même groupe de divinités - incluant l’important temple de lingapura, accueillant une image de Śiva, la Kanlon K. A. Anve Danle et le: K. J. Śrī Cảmpeśvara, image de Viṣnu -, renforce notre hypothesese

69. Voir par exemple, le K. I. Hariharailaya dans linscription k. 293 du Bayon (C.at)is 1928. p. 104: IC. III. p. 1931: ou le K. J. I.ingapura dans linscription k. 258 do Samrong (posterieure a 1020) saket : (1. II. p. 175).

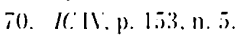

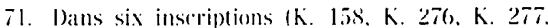
k. 237. K. 249 at K. 25tl. qui courent ume période

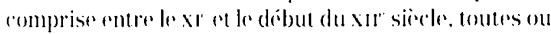
une partic deres divinités sont presentes. Il y est cueselion de lattribution de ressources au lemple do chapar Ransī. mais regalement. de facon récurrente. au temple do Sisa a l.ingapural loponsme fréquent dans lo corpus épigraphigue, qui designait, notammems. le temple de koh ker en colud de Vat Phu, voir /C: III. p. 971. 


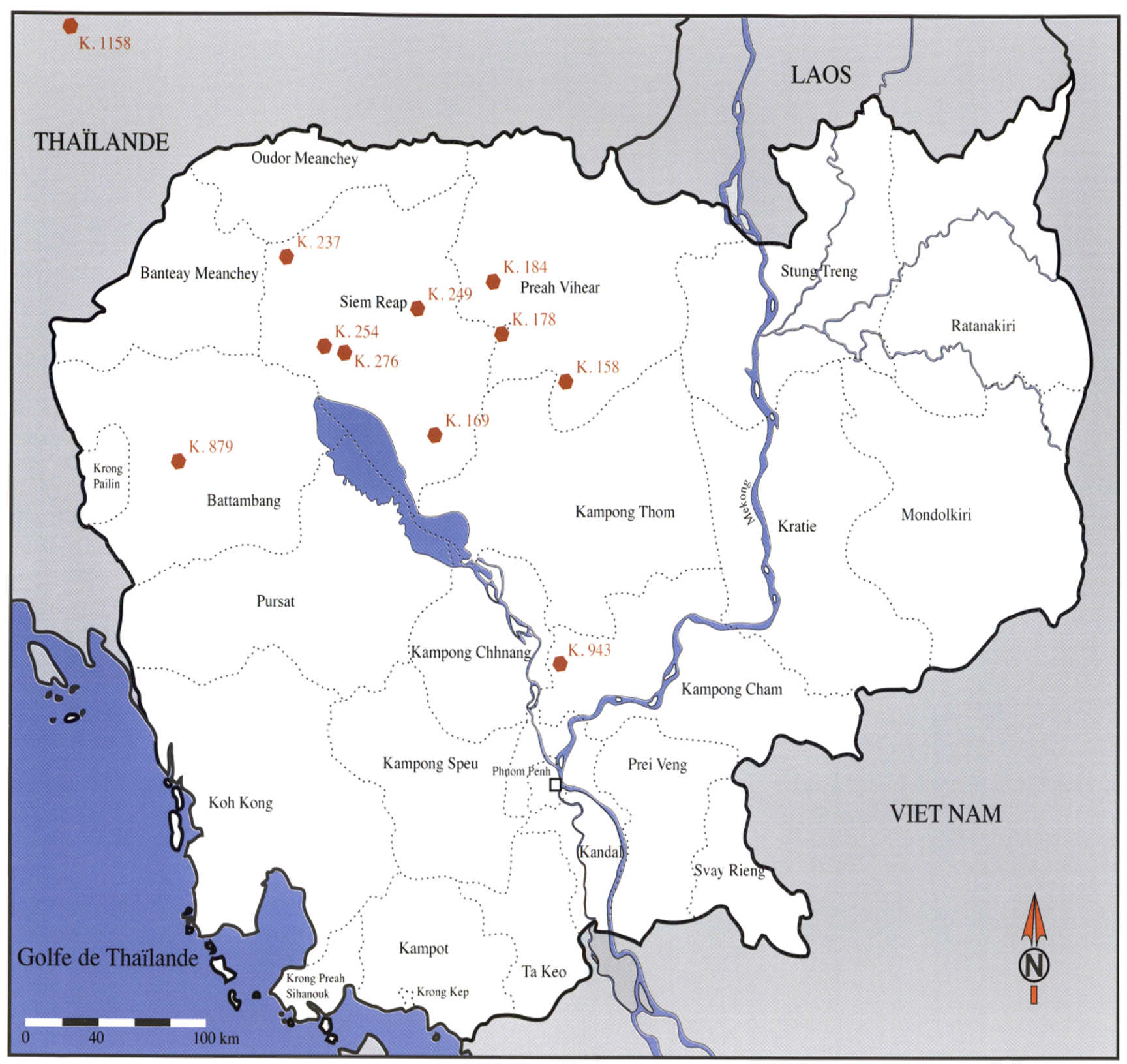

lïg. 15 : 1.ieux de provenanere des inscriptions mentionnant Chpar Ransī. frarte: Dominique Soltult.

Nous avons reporté sur une carte les lieux de provenance des inscriptions mentionnant Chpār Ransī, sans quaucun indice probant napparaisse pour identifier le lieu précis ou se dressait le temple originel de ('hpār Ransī (fig. 15). Nous remarquons néanmoins que linscription portíe par notre about est la seule à se situer dans le sud du Cambodge. I a plupart des références se rencontrent, en effet, dans le nord du pays et. plus précisément, autour de la région d'Angkor. Il faut mettro à part les inscriptions K. 879 et K. 1158 qui sont respectivement localisées dans la province de Battambang, à l'est, et dans la province de Nakhon Ratchasima, dans le nord-est de la Thaïlande. Relevons que cette dernierere région fut un loyer majeur du bouddhisme au cours de l'épocque angkoriennor?.

72. Voir entre antres. Hoomwand 2003, p. 10:-108.
Nouvelles données pour une dalation

$\grave{\Lambda}$ ce jour, la mention la plus récente de Chpār Ransī se trouve donc dans linscription K. 273 do Ta Prohmo ${ }^{73}$. stèle de fondation qui rappelle l'installation de plusieurs divinités par le souverain Jayavarman VII (r. (a. 1181-1218). Il y est ainsi demandé que l'on suive spécifiquement les coutumes du temple de Chpār

73. (:(1)1): 1906, p. 44. 
Ransĩ pour la célébration de la fête du printemps :

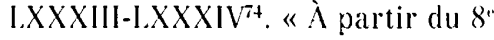
jour de caitra jusqu'à la pleine lune de ce mois, selon la tradition du Jina du Vaṃsárāma, la fête du printemps est célébrée chaque année, suivant la tradition de Bhagavatī ; on célèbre alors deux sacrifices avec tous les accessoires $»^{73}$.

Cependant, en se fondant sur la nouvelle lecture proposée, l'inscription K. 943 offrirait une mention encore plus tardive de C'hpār Ransī. İn effet, selon Philip N. Jenner, la forme chpar ranase que l'on trouve en ligne 2. avec notamment la présence de la voyelle e, indiquerait davantage une forme appartenant au khmer moyen ${ }^{76}$. Cette hypothèse nous a été confirmée par Michel Ferlus et Michel Antelme, bien que, pour ces deux savants, l'évolution linguistique que présente le mot ne se laisse pas totalement expliquer ${ }^{\bar{\tau}}$. Cette seule donnée linguistique fournirait donc un élément utile. pour dater l'inscription, même si le cadre chronologique concerné - l'usage du khmer moyen est conventionnellement daté du $\mathrm{Xv}^{*}$ siècle jusqu'au milieu du xvir" siècle - reste encore trop vaste. Par ailleurs, l'évolution de la langue khmère, indépendante des événements historiques, a été continue et sans rupture, et sans doute faut-il aussi prendre en compte la période charnière qui voit

7t. IXXXIII.

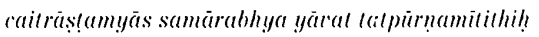

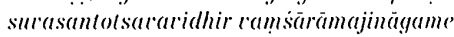

I.NXIIS:

rarșe earșe krtas tașyá bhagaralyā yathägumam pürnat! sarropakaranais tatra yätyadeayam krtam 7i. Fintivi: 2009 , p. 439

76. "In line 2 I see no problem with (...) chpara ranase. the " vowel being susgestive of Middle khmer f...l. The inherent a after the of of ramase need not surprise as since the rirama is nowhere used " leommunication persomenelle. féstier 20008$)$.

7i. En offet, |o changement $i|i:|>e$ le: en khmer moyen est regulier atu premier registre. mais dans les syllabes fermées par une consonne : en syllabe ouverte du premier registre le changement est normalement $i$ li: $>$ > i loil. lóvolution de ransi en ranase pourrat ôtre due, selen .ll. Ferlus. à une innovation isole deun lapiede qui aurait change i ren e pour tramscrire to ehangement bien ricel de prononcial-

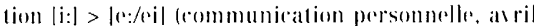
$2009)$. samorcer, dès le xiv" siècle, le passage du vieux khmer au khmer moyen ${ }^{7 s}$.

Outre l'inscription, la douille qui la porte et l'about qui s'y assemble offriraient d'autres éléments nous permettant de préciser la datation envisagée. Presque toutes les datations jusquïici proposées oscillent entre le début du xir" et le xurr" siècle ".7. Madeleine Giteau a, en revanche, identifié la douille, certes sans plus de précision, comme une pièce "nettement tardive " "son. Plusieurs caractéristiques, à la fois iconographiques, stylistiques et techniques, viennent à l'appui d'une telle hypothèse. Premièrement. il convient de mettre en parallèle notre pièce avec plusieurs abouts déjà étudiés ( ga j420). BTLS 648, I.B.386 et 350.2533i. Certains motif's décoratif's se retrouvent, telles les feuilles de lotus sur le trône: pourtant le décor de ce dernier semble sêtre simplifié, ne présentant qu'une séric de registres décoratifs et non plus un décor ajouré de lions et/ou de garuda atlantes. Or, ce motif spécifique de lions atlantes, figuré sur des socles dimages bouddhiques en bronze (Buddha, Vajrasattva ou encoro Hevajra), apparaît dìs le style du Baphuon (ca. 10101080) et continue à être attesté tout au long du style d'Angkor Vat. L'évolution iconographique observée serait donc au moins postérieure au XII" siècle, ce que confirmerait également la présence des nombreuses incrustations originellement prévues pour rehausser la douille. Colles-ci rappellent. en effet, un type de décor qui ne semble se développer qu'à partir de la fin du style du Bayon, soit au début du xIII" siècle" Deuxièmement, si l'on compare notre Vajrasattva avec les diverses représentations de la divinité connues entre le $\mathrm{XI}^{\prime \prime}$ et le xirl" siècle, celui-ci semble se démarquer du type iconographique traditionnel dont il constituerait également une forme évoluée. Ainsi, sur notre image, le bras droit niest

\section{Pot: 2004. p. HI-III}

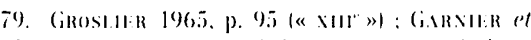

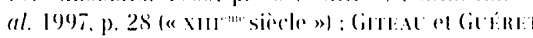

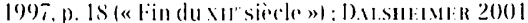

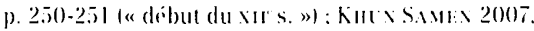

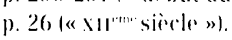

80. (illtat 1961. p. 222.

s1. (iाlid 1961, p. 222. plus ramené sur la poitrine mais s'en écarte légèrement. Quant aux jambes, clles sont toujours en sattcaparyanka mais cette attitude a été mal reproduite par les modeleurs. lo pied droit étant, en outre, clairement disproportionné Cette autre évolution iconographique permettrait de préciser encore la datation, qu'il faudrait done désormais envisager comme postérieure au xir" siècle. lítant donné l'une des particularités linguistiques de son inscription, notre about relèverait donc bien du XIV" siècle ${ }^{\text {*2: }}$.

\section{La stèle bouddhique du Vat Cheung Prey}

\section{Retour sur le lieu de découverte}

Dans l'une des fiches d'inventaire de l'objet étudié (n" I: 781), George Groslier donne la provenance suivante: « Envir(.) lonsl du vil(.)[lagel de Kradas, Chhöng Prei, Klomponlg Cham ${ }^{\mathrm{s} 3}$ ». Sachant que dans les fiches d'inventaire quïl rédige. George Groslier donne généralement, pour la provenance des pièces, dabord lo nom du lieu de leur découverte, puis ceux du district et de la province correspondants, " Chhöng Prei » serait ici le nom d'un district. Cependant, selon le découpage administratif en vigueur dans les années 1930. les limites de cet ancien district différaient de celles de l'actuel district de " Cheung Prey », puisquelles sétendaient alors plus ou moins sur ce dernier ainsi que sur ceux de Batheay et de Prey (hhor. Or, dans le district de Batheay et la commune de Tang Krasang existe aujourd'hui un village nommé Kradas. Il ne fait done aucun doute que notre pièce provient des "environs" de ce village, ce qui, au vu du caractère essentiellement mobile de l'objet. ne lournit

\$2. L ne meme datation peut îte preposée pour atu moins deux autres abouts déjà cités tga $5+23$ et le Lajasattra du Palais Roval do Planom P'enht. qui parlagent plusieurs traits communs. à la fois ienographicques. stylistiques al terhmiquess, aree notre objet.

83. Georon cordes reprend. plus tard. cente information dans le volume VIII de se's Insiriptions du cambodge 1/C. YIII. p. 216), mais le village, loujours localisi dans la provinere de kompong cham, y est alor's nommi " phum krabas" 
toutefois pas pour autant un contexte précis. Cependant, un témoignage archéologique invite à penser quelle a originellement servi au sein d'un sanctuaire situé à environ cing kilomètres plus au sud-est.

\section{Le Vat Cheung Prey : sanctuaire d'origine?}

Le site qui nous intéresse ici est la pagode du Vat Cheung Prey (IK 103.01). implantée à 200 mòtres à l'est du villago de Cheung Prey fommune de (heung Prey, district de Batheay). (ee site n'a que très peu attiré l'attention des premiers chercheurs de la fin du xix" siècle. Ainsi Étienne Aymonier mentionne-t-il « une statue de lion et quelques blocs taillés de limonite», en ce lieu où « fut peut-être construit jadis un temple brahmanique $»^{* 4}$. Etienne Lunet de Iajonquière ne donne guère plus d’informations : "On y conserve quelquess pierres sans grand intérêt qui proviennent certainement d'un monument ancien : ce monument était-il situé à cet emplacement même ou dans les environs? Il nous a été impossible de tirer à ce sujet auceun renseignement du chef des bonzes $n^{\text {s.j. }}$. Le récit que Robert Dalet fait de sa propre visite en 1934 complete heureusement ces premières descriptions. C"est, notamment. grâce à cet auteur qu'est publiée pour la première fois une stòle bouddhique en grès. qui doit être intégrée à la présente étude. R. Dalet donne une description détaillée do cette pièce, qui est alors conservée avec d'autres sculptures au sein de la pagode:

"Sur lautel, une curieuse stèle montre un näga dressé sur deux replis et dont le. haut et gros corps renflé porte sept tôtes do dragon. Dans lo capuchon du reptile est creusée une niche cétroite ent longue qui a dû recevoir un personnage debout. probablement en métal : actuellement, il ny a plus qu'un petit Buddha, peut-être en ciment, attestant la terre. placé au bas de la niche. Au-dessous se voit un lotus (?) en demi-cxul posant sur le repli supérieur du serpent. la naissance de l'ogive de la niche parât être

S4. Tryoviln 1900. p. 318.

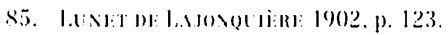

dans les mains de deux femmes placées de chaque coté el dont on ne voit que le buste. Sous ces figurines et un peu à lextérieur. deux demi-ovoïdes pointus sont peut-ôtre encore des lotus. Les cous du nāga sont rayés ; chaque tête a une rosace derrière et la queue se relìve dans lo dos jusqu'à entamer lo grand cercle dorsal, en partie usé La hauteur de cette stèle est de $1 \mathrm{~m} .05 »^{\mathrm{xt}}$.

Cette description s'aceompagne d'une photographie unique de la stèle, qui constitue désormais un document précieux pour son étude (fig. 16). Toujours conservée sur place, la stile a. en effet. subi d’importantes modifications. Sa surface a ete entièrement recouverte d'une epaisse couche de peinture doré, alors que plusieurs têtes du năga ont été brisées au niveau de leur partie supérieure (fig. 17). Ce sont là autant de transformations qui gênent aujourd'hui sa lecturesĩ

Décrite comme "curieuse " par R. Ialet, elle se distingue des autres stèles bouddhiques connues non seulement par sa forme générale représentant un näga, mais aussi par sa longue niche centrale, étroite et sélargissant vers lo haut. Celle-ci mesure rnviron quarante-cinq centimètres de haut et une quinzaine de centimètres de large dans sa partie supérieure. Ie petit Buddha et le support sur lequel il repose étant clairement des ajouts modernes, cette niche ne devait à l'origine présenter qu'une seule cavité dans sa partie supérieure, sculptée en léger creux. Co sont sans doute ces ćléments qui ont conduit R. Dalet à penser que la stèle " a dû recevoir un personnago debout, probablement en mélal » (nos italiques). Toutes ces données se rejoignent et font étonnamment sens si lon considere à nouveau notre about : par sa forme générale, ses dimensions ainsi que son matériau.

\footnotetext{
86. 1).11.191 1936, p. 48-49.

s7. Vous avons pu observer la stele lors d'une visite

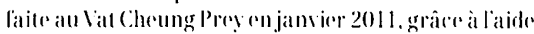
de corra Socheat de livedier de conservation-restateration de sculpture du MVVC. Auparavant dreposce sur puis desant lautel primeipal du rihöra ou elle laisail lobjet d'un culte ainsi que plusienurs autres image's dlu Buddha, colle a cilr mise a lab)ri dans la chambre de limérable de la pagode depuis le débul des travaux de reronstruetion de lancien vilhäre.
}

il correspondrait parfaitement à l'image originellement prévue pour cette niche. Nous pensons quil aurait été déposé au sein do celle-c:i, l'image de Vajrasattva venant certainement se caler dans sa partie supérieure où certains ajustements semblent avoir étó spécialement aménagés dans la pierre pour la recevoir. Le petit tenon plus ou moins cylindrique sculpté en relief au centre de la stèle aurait, quant à lui, regu la partie inférieure de la douilless.

lin son état actuel. il est difficile de dater précisément cette stèle. Chronologiquement, rien ne s'oppose toutefois à un rapprochement avec notre about. à dater du xiv" siècle. rappelons-le. Ainsi les deux personnages féminins sculptés de part et dautre de la niche centrale pouraient très bien être contemporains de celui-ei. Ils sont figurés non pas en buste comme le rappelle R. Dalet mais en attitude denvol, coiflés comme l'image de Vajrasattva d'un diadieme et d'un couvre-chignon, et portent très certainement des offrandes. A quelques détails près. ces deux personnages sont identiques aux figures, elles aussi féminines et en attitude d'envol (apsara ?), qui apparaissent, à partir de la premiere moitić du xur" siècle et jusquà répoque post-angkorienne, au sommet do plusieurs frontons à scènes illustrant la carrière du bodhisattea ou encore la vie: du Buddha ${ }^{\text {s". }}$. De la même manière, le nāgga avec lequel la stèle se confond pourrait, lui aussi, être contemporain de l'about. Il est, en effet. à sept têtes, alors que son corps forme trois anneaux - et non pas deux comme le décrit R. I)alet. Or, il s’agit là d’un type classique de représentation attesté des

\footnotetext{
ss. Cette association de laboul a de la stele ne

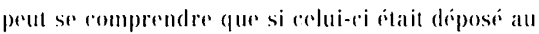
soin de la niche salns son cherent let. supra p. 137). Ce dernier. mobile, aurait ele seulement lixe a l'about lorsquil reat utilisc comme enseigne. lat niche de

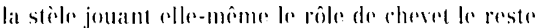
du temps. I:n outre alu va de la forme légierement concave de la niche, il est fort possible que la douille ait ér montere a linvers. seule lainseription étant

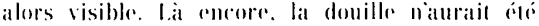
remonter à lendroil que lors des processions.

89. Voir. par exemple. Rovedos 2005, lig. 6.59 IBantealy Samre : fronton est de la bibliothegue sud, premiere moitio du xur sierle) 6.ts (Banteay

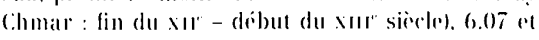

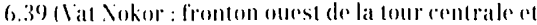
fronton e'st du sanctuaire central, xire sierelel.
} 


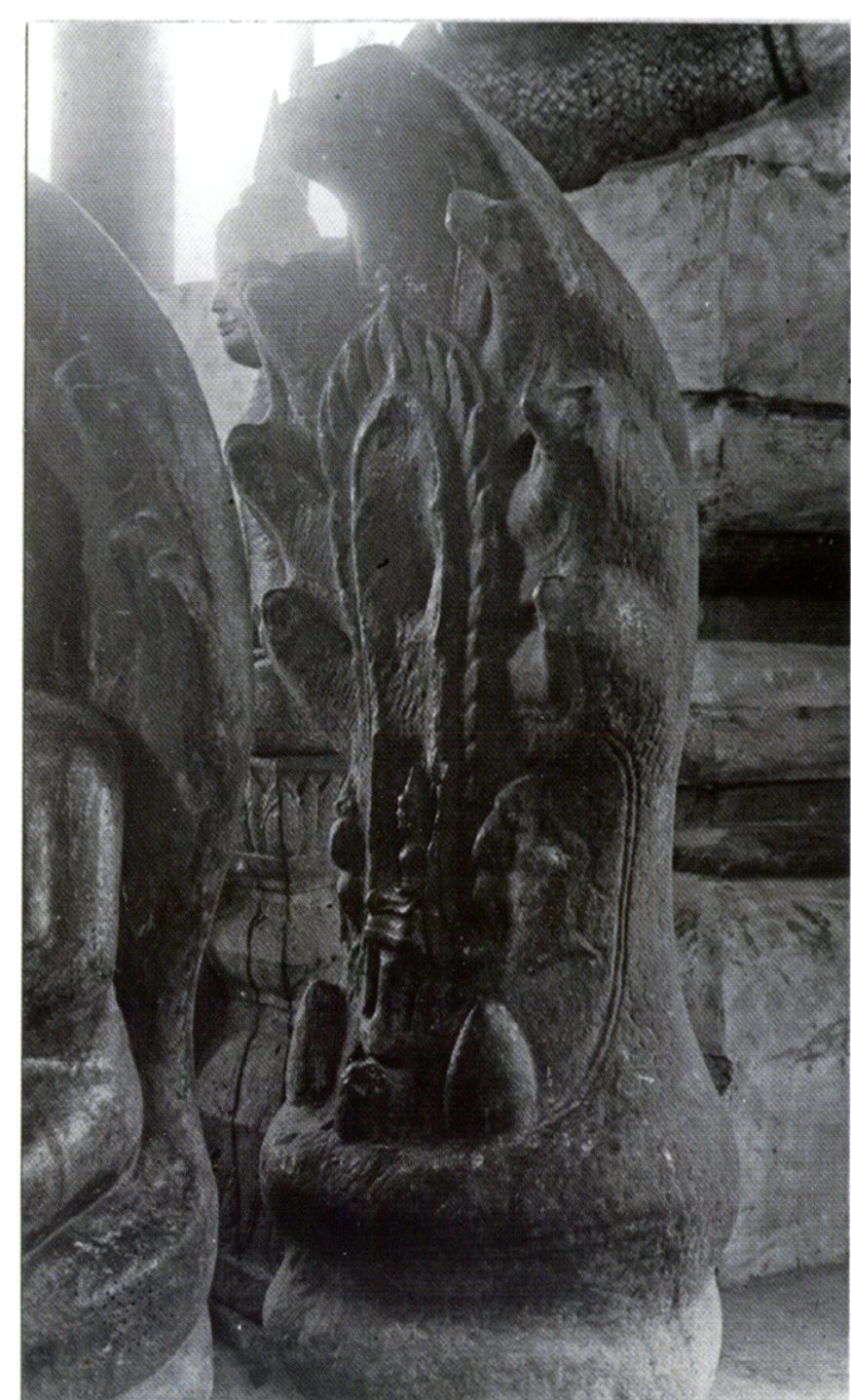

Hig. 16: Stele bouddhique déposece sur lauted du Vat cheung Prey Idistrict de Batheay, provinere de hompong (ham). (photo : Ecole francaise d'lixtrôme-() rient. Fonds (ambodgo. rat. (..1M 15845_a2).

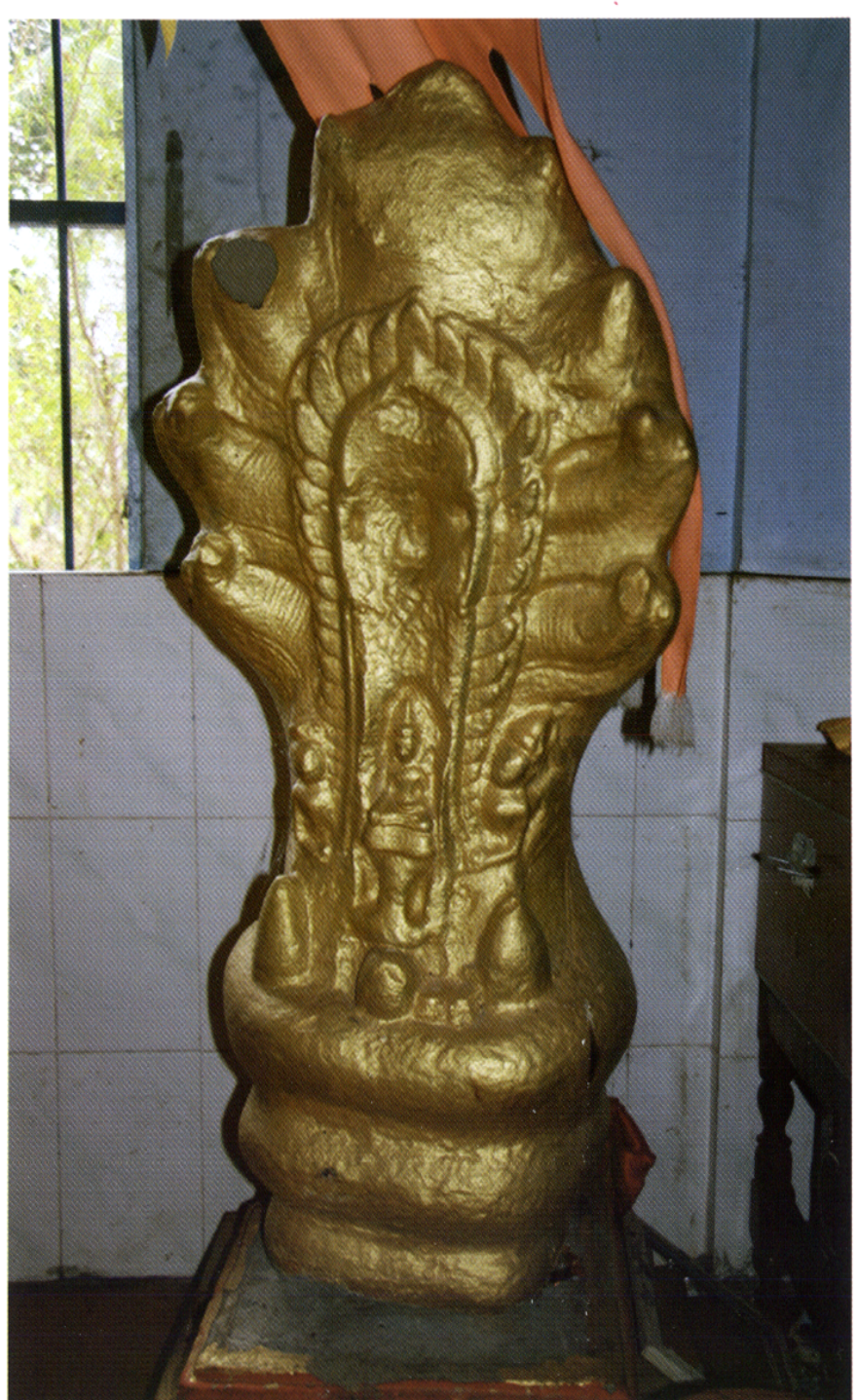

Fïg. 17 : Stèle bouddhique en forme de nägat.

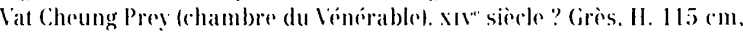
(photo: Brice Viscist) le XI" siècle el au moins jusquà la fin de. l'époque angkorienne pour les images du Buddha protégé par le nāga. I)'autre part. il n'est pas impossible que les deux motifs "ovoïdes » ou coniques sculptés en relief. rux aussi de part et d'autre de la niche centrale, soient identifiables à des offrandes. Un argument allant dans ce sens est fourni par des images en bas-relief de rsci sculptées à la base des piliers de la galerie de's bas-reliels et du préau cruciforme du temple dingkor Vat. Sur chacune de ces images - tout du moins sur celles où le relief est conservé -. deux motifs coniques analogues à ceux do la stèle sont figurés sur des sortes do supports et représentent très certainement des offrandes de nourriture destinées aux ascètes" (fig. 18).

I.̈idée que notre about allait de pair avec la stèle du Vat Cheung Prey - qui, contrairement à celui-ci, nà vraisemblablement pas été déplacée sur de grandes distances - vient done appuyer l'hypothese selon laquelle il aurait servi dans lancien sanctuaire, peut-être bouddhique, situé à lemplacement même ou aux alentours de cette pagode"1. Cette association suggère,

90. Siyonn Sophearith. rommunication porsonnelle, janvier 2011

91. Dans la notire quäl consarere on juin 2007 au lal Cheung Pres: le site intermet do la carle Interactiere des

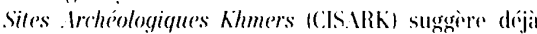

en outre, quien dehors des processions où

crefe provenance pour notre about - reconnaissable grâce à des photographies darchives -, sans pour autant domer dexplieation le lieu do provenance probable d'une piere dabout en bronze déororé d'une divinité maseuline ». P'ar ailleurs, outre la stede bouddhigue deja presenter - et plusieurs images modernes du Buddha-dautres silements de sculpture et de dereor architerfural en grios. presgue tous fragmentaires, somt inventeriés : doux statues de lions, des frigments de colonnetles ortogonales ainsi que divers piedestatux. seule une partie de ces pieces est aujourd hui visible sur le site. Il sagil la des seuls vestiges de l'ancien sanetuaire qui. comme nous liavons dit, se trouvait tress cere lainement en ce lieu ou à proximité Tous se rattachent a läpeque angkorione et temoigneraicon de plusieurs ocrupations sucerssives, meme sil reste dilficilo de les dater de maniere precise. Finfin, une stele bouddhique est. certes associón à ce sanctuaire. mais il ne semble pas pour autant possible de se prononce." sur loberdience religiense de ere dernier. 
il aurait servi denseigne. l'about. et done: l’image de Vajrasattva, élait conservé au sein d'un temple, où, déposé au centre l'une stiele, il lacisait sans doute lobjet d'un culte. Certes, labout se distingue assez. nettement, tant par sa forme que par ses dimensions, des ulsavamürti ou statues de divinités portatives utilisées dans les fêtes et les processions, telles qu'elles sont connues par l'épigraphie et par quelques statues dès lépoque préangkorienne et tout au long de l'époque angkorienne. Il ne semble pas pour autant impossible que notre about, à la fois image de procession et image de culte, ait appartenu à cette catógorie ${ }^{92}$. (ieorge Codès ${ }^{93}$ avait développé l'idée que ces divinités mobiles étaient destinées, au Cambodge comme en Inde, à « représenter dans les fêtes et les processions les statues inamovibles installées dans les sanctuaires » et quoelles étaient, en tant que reproductions fidèles des statues en pierre, équivalentes à un « original » demeurant dans le temple. Si notre hypothèse est exacte, il faut supposer que notre pièe, image portative en bronze, possédait peut-être une sacralité égale à celle des images en pierre des temples.4.

Les liens du K. J. de C'hpär Ransĩ avec le bouddhisme lantrique

En résumé, nous serions done en présence d’une ulsacamürli représentant Vajrasattva, qui aurait été vénérée. dans laneien sanctuaire localise sur le. site du Vat cheung Prey ou à proximité.

92. Sur les ulsaramurti dians le Cambodgre ancien.

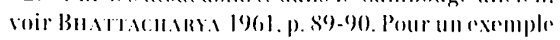
unique d"utsaramürti khmore du s" sierle, reremment arequise par te musere (iumed (1): 1 2276), voir alussi BAPTISTE 2010.

93. C(t)it:s 1923. p. 12.

94. Celte presupposition dume satraliti plus importante des statues en pierere que des statues en

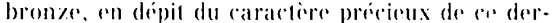
nier matériau, semble avoir en une certaine populatrite dans les études khmores froir. entre allters.

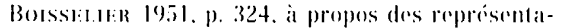
tions de Vajrapainil. Porurtant. en Inde et notam-

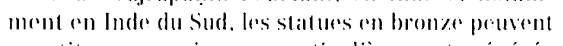
constituer une imagre particulierement vinerése

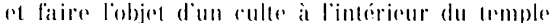
(1)ominic Goodall. communication personmelle. decembre 2010 : voir alussi (iuy 2006, p. Is).
Rappelons que l'inseription K. 943 demande que les gens qui servent auprès du K. J. de C'hpār Ransī donnent l'about à un dénommé $̂$ vapandita, serviteur dans un autre temple qui correspondrait à cet ancien sanctuaire du Vat cheung Prey lcf. supra p. 148). Notre about aurait donc été transféré depuis le temple bouddhique de Chpār Ransī pour les besoins du culte. Cependant, l'épigraphie fait également mention de "doubles de divinités », c'est-à-dire des divinités dont les représentations sont faites à l'image d'une divinité principale, sans doute dotée d'une sacralite forte. Ces doubles peuvent, en outre, porter un nom différent et revetir une autre apparence ${ }^{95}$. Or, nous savons que le K. J. de Chpār Ransī. en particulier, possédait des doubles. Par exemple, la statue de lokeśsara nommée Śri Samantaprabheśa que mentionne l'inscription K. 158 de Tuol Prasat (100)3$1004)^{\%}$ aurait bien été faite à l'image du K. J. de Chpār Ransī, dont l’image de culte était un Buddha, rappelons-le ${ }^{97}$. Selon nous, la seule divinité citée dans l’inscription K. 943 étant précisément lo K. J. de Chpār Ransī, il se pourrait que notre about soit l'un des doubles de. cette divinité. Il aurait done été donné au dénommé Āvapandita afin que l'ancien sanctuaire du Vat Cheung Prey soit doté, à l'échelle locale, d'une image de celle-ci, mais cette fois-ci sous la forme d’un Vajrasattva. À l’appui de cette hypothèse, l’inscription K. 1158 suggeriait déjà l'existence d'un lien fort entre le K. J. de Chpār Ransī et le bouddhismo tantrique. lin effet, si les deux premières stances de son mangala s'adressent, respectivement, aux cinq Buddha transcendants (jina) et à Vajrasattva (cf. supra p. 136), les stances $V$ et VI expriment quant à

95. Sur les doubles khmers de divinites indiennes renommers, notamment, wir Savblekson 2003$2004.0 \%+403$

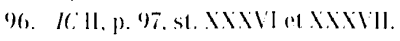

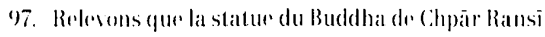
est exalement nomméne dans cette mêne inseription, Śri Samantaprabhesa. la divinite at som double portaicut done le même nom (listivis 2009 . p. 349-3.5.5. elles un vibrant hommage à cette divinité renommée.

Notre about aurait donc śté le double du K. J. de Chpar Ransĩ en mème temps qu'une utsavamürli, cette image portative ayant été vénérée à la fois à l'extérieur du temple et au sein de celui-ci. Il reste toutefois à savoir si une utsavamürti peut concentrer les fonctions d'image de procession et de double de divinité. Une utsavamūrti peut-elle, en outre, résider et faire lobjet d'un culte dans un sanctuaire différent de celui où se trouve l'image qualle reproduit?

\section{Conclusion}

$\Lambda$ dater du xiv" siècle, labout inserit du MNC: aide à mieux comprendre l’importance du culte qui a cété rendu au K. J. de Chpār Ransī. Attestó dès le $x^{\prime \prime}$ siècele et peut-être même dès la fin du $\mathrm{IX}^{\prime \prime}$ en prenant en compte l'inscription K. 682 de Prasat Thom, celui-ci serait, en effet, toujours pratiqué au xiv" siècle. Le temple de Chpãr Ransĩ aurait done été affilié au bouddhisme pendant au moins cinq siecles, ce qui constitue un exemple rare dans l'histoire religieuse du Cambodge ancien. Une telle continuité soppose à la conception communément admise d’une religion bouddhique s'étant manifestée de manière épisodique à l'époque angkorienne et sous la forme dépréciative d'un « bouddhisme syncretisant »". Fille témoignerait également en faveur du statut et de la sacralité hors normes de ce temple. sans doute protégé et encouragé par les souverains angkoriens successifs ou par quelques dignitaires.

l.e temple de Chpār Ransī constitue done: un exemple rare sans etre pour alutant exceptionnel. Ainsi, à l'échelle de la région de Kompong cham et de ses environs - doù notre about provient i] serait possible dobserver de la même maniere une présence ininterrompue du bouddhisme et. plus particulièrement, du bouddhisme tantrique, depuis le $\mathrm{x}^{\prime \prime}$

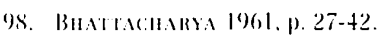




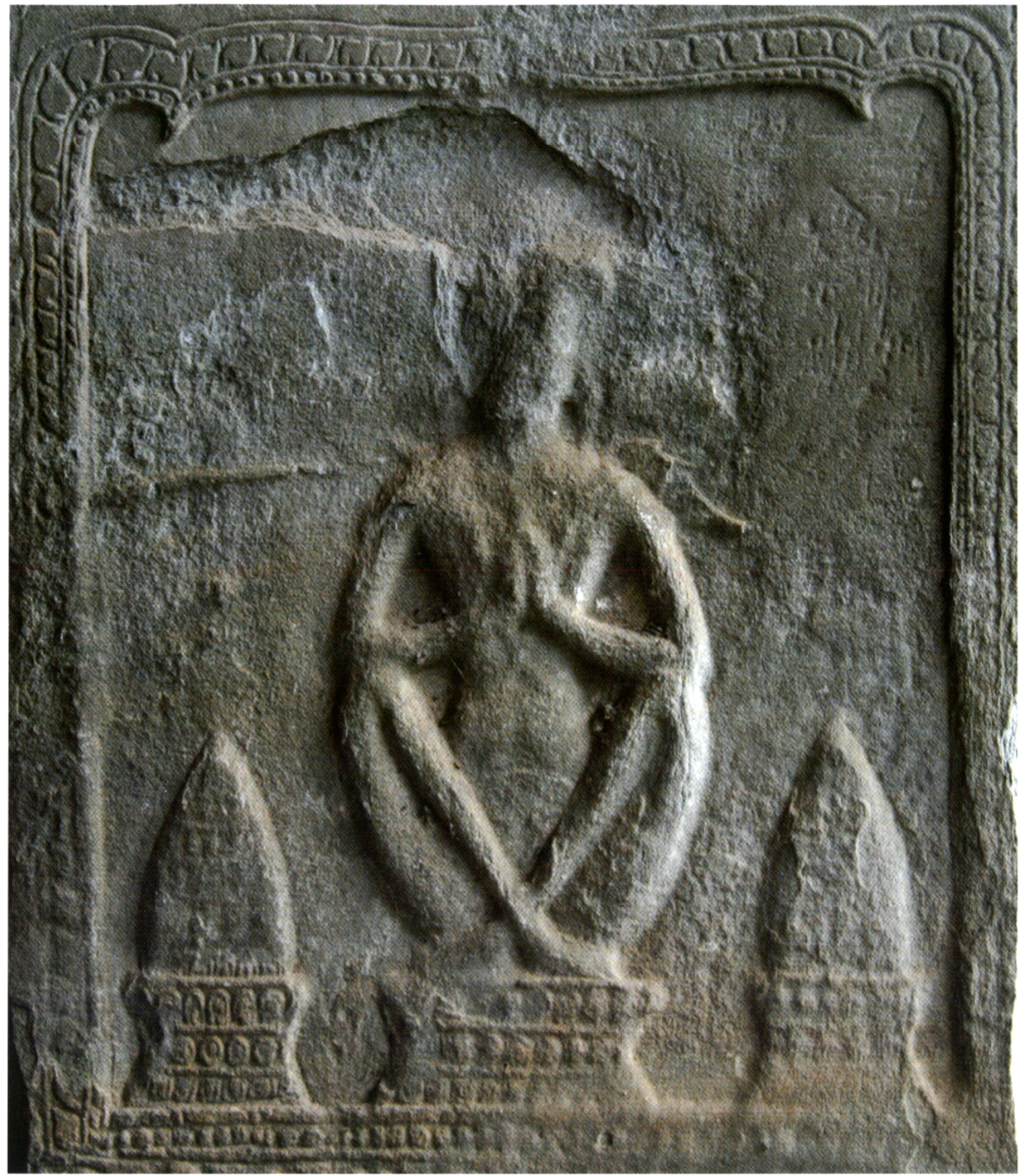

lïg. 18 : Rși entouré doffrandes (?). Bas de pilier de la galerie des bas-reliefs, Angkor Vat (provinee de Siem Reap). Première moitic du xil" siêcle. (Grès. (photo : Brice VInctent).

jusqu'au XıV" siècle (fig. 19). La fameuse stèle de Vat Sithor (K. 111), datée de 947948, pose un premier jalon pour l'histoire du bouddhisme tantrique dans cette région du Cambodge. Or, la pagode où elle a été découverte (IK 123), située dans la région de Srei Santhor, ne se trouve qu’à soixante-quinze kilomètres au sud de celle du Vat Cheung Prey, lieu d'origine présumé de notre pièce. Plus près encore, sur le Phnom Trop, colline située à moins de dix kilometres au nord-ouest de cette dernière, a été mise au jour une triade bouddhique, qui est aujourd'hui exposée au musée Guimet (MG 14880, MG 14892 et MG 14912). Datée du troisième quart du X" siècle, celle-ci a été récemment reconstituée et représente lo Buddha, Lokeśsara et, pour la première fois en ronde bosse. Vajrapāni»". Entre autres témoignages de ces débuts du bouddhisme tantrique dans la région, il faudrait encore mentionner la stèle bouddhique du Vat Preah Houch (IK 84.03) qui, apparentée à l'ensemble de steles du Phnom Srok, serait, clle aussi,

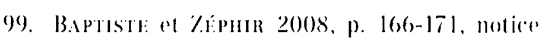
$n "+8$. à dater du $x^{\prime \prime}$ siècle ${ }^{100}$. Plusieurs autres vestiges bouddhiques sont encore attestés dans la région de Kompong Cham et ses environs du XI" au XIrI" siècle. Pour le culte tantrique, il convient de citer, en particulier, deux paires d'abouts - déjà étudiées - portant des images du Buddha paré protégé par le nāga (ga 4057 et 5593 ; ga 2939 et 4444). Datées du xir" siecte, elles seraient toutes deux originaires du district de Prey Chhor, voisin

100. D).1.1 1936, p. 45-46, pl. 9-B : Bolsseinen 1966, p. 98, n. 4 
de celui de Batheay où est situé le Vat Cheung Prey. Non loin ont été, en outre. fondés les importants sanctuaires mahãyäniques du Vat Vokor (IK 85) el du Prasat Kuk Yeay Hom (IK 88) : le premier est une fondation bouddhique du souverain Jayavarman VII et il pourrait en être de même du second "'I. Infin, les témoignages les plus tardifs de la présence du bouddhisme tantrique dans la région seraient fournis non seulement par notre piece, mais aussi par un autre about décrit plus haut (ga 5423), lui aussi à dater du xiv" siècle, qui a été mis au jour plus à l'est. dans le district de Thong Khmum. La région de Kompong Cham et ses environs aurajent done constitué au fil des siècles un important loyer du bouddhisme, dont l'activité religieuse aurait encore perduré au-delà de l'époque angkorienne pour se conlondre aver: le nouveau culte theravadin, ce dont témoignerait, notamment. locecupation continue des sites du Vat Nokor et de la région de Srei Santhor à l'époque post-angkorienne.

Julia listeve, lipHli:102 esteve.juliagyahoo.fr Brice Vincent, Université Paris $3^{103}$ bricevincent@yahoo.lir

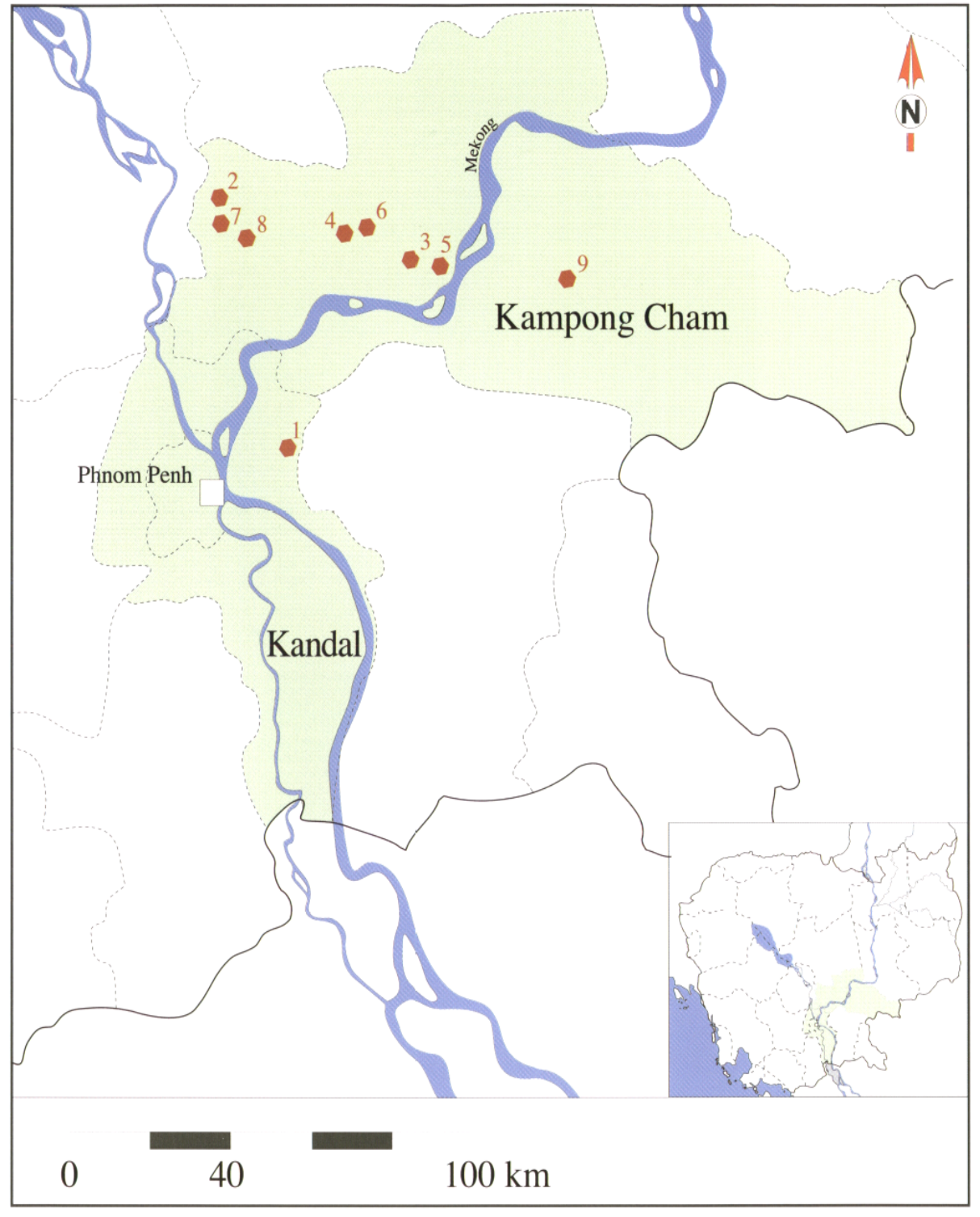

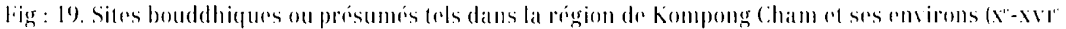
sieclest. (ratro: Dominicgur Sot Thl).

I Vat Sithor (distriet de Ksallh Kandal) 2. Phnom Trop (distriet de Batheay) 3 Vat Preah Ilouch (district de Kompong Siem) 4 Russeri Pontea Idistrict de Prey (hhor) 5 Vat Nokor (district do Kompong Siem)
6 Prasal kuk Yoay Hom (district do Prey Chhor) 7 Kradas (distriet de Batheay) 8 Vat Cheung Prey fdistrict do Batheay) 9 Kor (district de Tbong Khmum)

I01. I,a question de lautribution du Prasal kuk

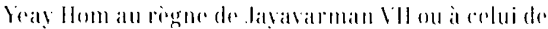

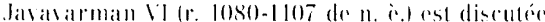

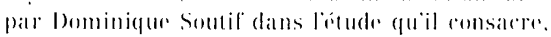
au sein de re meme dessier. as un pendentil inserit

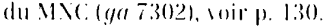

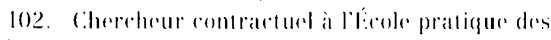
hautes chudes. Paris.

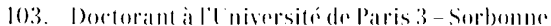
xouvelle. 


\section{Bibliographie}

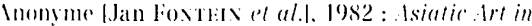
the Yuselum of lime Irts. Bostom. Boston (Nass.t. Muserum of line Arts.

Iryoxil: Étienne. 1883: " ()uelques notions sur les inseriptions en vieux khmer". Journal . Asiatique $8(1)$, p. $441-50) 5$

- 1900-1904: le Cambodge. 3 rol. Paris. I: l.croux

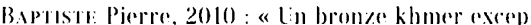
tionnel permet d'illustree un type d images de procession jusqualor's inédit ", la Revele des Husées de lirance. Rerue du lourere 60 (3). p. 6-7.

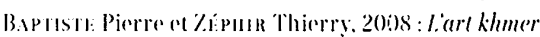
dans les collections du musée Guimet. Paris. Reunion des musées nationaux

Barxaru Noel (éd.). 1978 : Seren Bronzes from Southeast Asia and Indomesia, Part One: Tue k'there Bronzes, Canberal, The dustralian National Gallery.

Bartil Auguste, 1885: Inscriptions sanscriles du Cambodge, Paris, Académio des inscriptions a belles-lettres I. Votices at extmaits de's manuscrits de la Bibliotheque nationale el atuters bibliotheques. $27-11$, p. 1-180.

Bl:Rcialcixl: Abrl, 1882 : "lne nowvelle inseription cambodgiemur »|K, 139|. dournal isiatique 7 11). p. $208-232$.

- 1884: "Chromolegrie de liancien royaume khmer d'apres les inscriptions $"$ |K. 237. K. 287 a k. 1731. Journal Asiatique' 8 (31. p. $51-76$

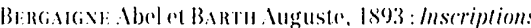
sanscrites de Campä el du Cambodge. Partis. Academio des inseriptions a bolles-ledtres Cotiers at extraits des manuserits do la Bibliotheque nationale el atres bibliothergues 27-2). p. 181-632.

Buatacanora Benoytosh. 1964: An introduction to Buddhist esolerism. Varanasi. (Chowkhamba Sanskril Series office.

BHondendra kamaleswar. 1961: Les religions brahmaniques dans l'ancien Cambodefe diaprè: lépigraphie el liconographice. Paris. Billio(

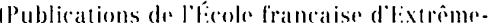
Orient 49).

Bolsstortzo Jean. 1951 : " Vajrapani dans laurt du Baycon ". in Proceedings of the 2-2nt Congress of Orientalists, Istanbul, (). Y. Matbīsi, p. 324-332

- 1960: Asie du Sud-list. I. Ie Combodge. Paris. 1. e. J. Pieard ot Cie I Manuel datrehrologie d'Fixtrime-()rient)

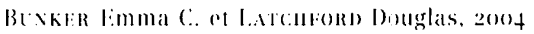
Idoration and cilory: The ciolden . lge of Khmer 1rt. Chicago. Arl Vedia Resourees.

(aidis George. 1906 : "l.a stiole de Ta-p'rohm * IK. $2731 . B 1: F /: 06(1-21,0)+4-86$.

- 1908: " les inscriptions de Ball cum (Cambodgen) | K. 266, K. 26i rt h. 26,8], Journal 1siatique 10)(12). p. 226-2:2.

- 1923: Bromzeskhmers. linde basésesur des doru. ments recueillis par .17. I. I.eferere-pontalis dans les collections publiquese el priciess de Bangkok "t sur les pieces conserveres aul lalais Roygal de

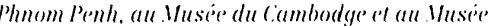

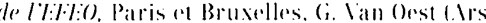
Isiatira 31 .

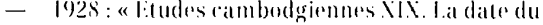
Bivon" |K. 293|, Bl:Fl:0 28 11-21. p. 81-112.

- 1931 : “ ludes cambodgiennes XXV1. la diat

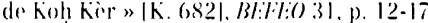

- 1942: "Ln dorument capital sur le bouddhismo rn Indochine : la stiple de Vat Sithor" |K. 1111. in Studies on Buddhism in Japan t. p. 110 squ.

- 1952 : " Ln rantra récemment découvere a Angkor" ". Journal A sialique 240 H1. p. 46ij-4izi.

- 1961 : "les expressions rrah kamraten añ "1 kamraten jagal en vieux-khmer". The ddyar library Bulletin 2.5(1-+1. p. 447-460).

- 1937-1960 : Inseriptions du Cambodye, s vol. Ilanoi el Paris. I:Ii:0 lCollections de textes ot documents sur l'Indorhine 31.

Coomanosway Inanda kentish, 1924-1926: "Catalogue des pieces khmores conservies dans les museres dimérique du Nord ", Irl al archeologie khmers 2 (2). p. 235-240).

(ont louise A. el Jert Paul féd.), 2010 : Gods of Ingker. Bronzes from the Vational Vuserum of Cambodia. Washington, liniversity of Washington Press.

Coterix Paul, 1988: " la fouille du Sras-Srang », in

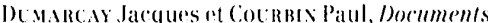
araphiques de la conservalion dingkor 1963. 1973. Paris. HElio (Collection de textes et doruments sur l'Indochine 17), p. 21-44.

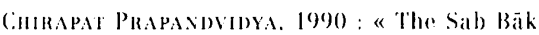
Inscription: Ridence of an Rarly Vajrayaina Buddhist Presenere in Thailand $\$ \mid k$. $1158 \mid$. Journal of the Siam Society is (2), p. 11-14.

DA.1T Robert. 1936: "Recherches archélogigues au Cambodge ", Bl:IF:0 $36(1), 1), 23-64$

D.M.sH: Imer Vadine, 2001 : les collections du musse national de bhnom leenh lart du cambodye ancien lavere une introd. de Brumo Dacilixs).

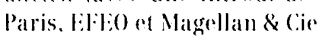

Dowtove Vance H. 1996: "Ilonolulu Academy of Art Tenth-Century Khmer Buddhist Trinity". Artibus isiae $56(3-4)$. p. 325-341.

Estive Julia, 2009 : "Étude eritique des phenomenes de syncrétisme religioux du Cambodge ancien ". 2 vol.. these de doctorat (9) inillet 2009). P'aris. I:Plll:.

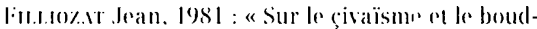
dhismo du cambodore a propos de deux liveres

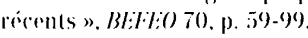

Pivor louis 1925: "Lokeresara en Indochine" in

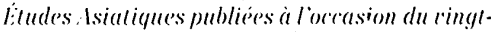
cinquieme annicersaire de lito le fronscaise d lixtreme-()rient, laaris el Bruxelles. (i. Van ()est. p. $227-250$

loxjtis Jan el al. 1992 : Selected Masterpieces of

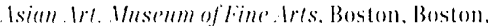
Museum of line Dits.

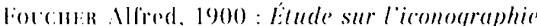
bondelliegue de l'Inde, d'apres de's documents nouceaux. Paris, 1. I.eroux.

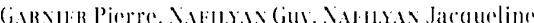
ol Ckis Christian. 1997: l:1rl khmer an silue. lion de resertes, Marseille, Iditions ruroprénmes Marscille-Prosenes

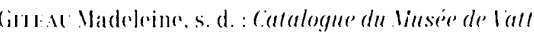
Bodhi lâl.

- 1961: " Vote sur un Garuda réremment emere atu Vusere national de Phomom-Pronh n. Ir/s Isiatiques s (3). p. 215-226
- 1965: les khmers. Sculptures khmeress reflets de la civilisation d'Ingkor. liribourge Olfice du livre.

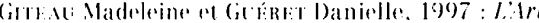
kllmer. Tresors du Cambodge. Paris, Somogy.

Coloulb1:N Virtor. 1937 : "Sur quelques images khmeres de Vajradhara ", Journal of the Indian society of oriental :1r1 5. p. 97-104.

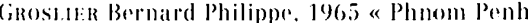
Vusere des bronzes khmers". Connaissance des (ar/s 164. p. $90-97$

Ginosill1: George. 1921 : Recherches sur les Cambodgiens, diapres les textes et les momuments depuis les premiers siedes de notre ère. Paris. 1. Challamed

- 1924: Calalogue général du Vusée du Cambodge Masé Iberl Sarraut). Hanoi. In:mprimerio d'ixtrôme-() rient.

- 1931: less collections khmereses du musée HbertSarraul à Phnom Penh. Paris el Bruxelles, (i. Vall Gest IArs Asiatica 16$)$

(iti) John. 2006: "Parading the Gods: Bronze Derotional lmakes of Chola South India ", in

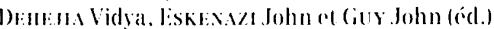
Chola. Sacred Bronzes of Soulhern India. I.ondon. Roval Arademy of Arts. p. 12-25.

- 2010 : "Angkorian Metalwork in the Temple Setting: Icons, Arehitectural Adormment, and Ritual Paraphernalia ", in CokT ot Jlor fíd. 2010. p. $88-129$

How Is lloward c 1948 : "A Javanese bromze" The Bulletin of the cleveland Vuse'um of tre 35 (8). p. $187-188$.

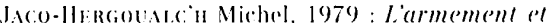

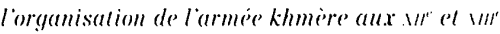
siecles : d'apries les bas-reliefs dingkor lat. du Bayon el de Bantean C.hmar. Paris, Pre'sse's unirersitaires de lirance.

Jasous: (laude, 1971 : "Supplément au lome VII des Inscriptions du Cambodge" BLFIO 58 p. $177-195$.

- 1982: "Vourelles orientations pour l'étude de l'histoire du pays khmer ". Isie du Sud-list el monde Insulindien $13(1-4)$. p. 39-57.

- 1994 "Les kamrateri jagat dans l'ancien Cambodge m. in Broot l rançois (dir.). Recherches nourelles sur le Cambodge. Paris, I:IEDO. p. $213-225$

Jixven Philip X.. 2009) : A Dictionary of Lngkorian Khmer Canberra Pacilic Linguisties, Research Sichool of Pacific and Asian Studies. Australian Vattionall Lniversity

Jesste Helen I.. 2006 : Masterpices of the Vational lusesum of Cambodia. l'hnom Penh. liokel.

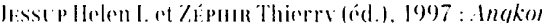
"l dix siede's d'art khmer. Paris. Reunion des musfies nationaux.

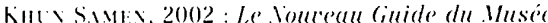
lational. Phonom Penh. Toyota londation.

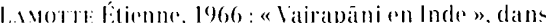
Vélanges de sinologie offerts à lonsiener Paul Demiceville. Paris. Presses universitatres de liane. p. 113-159.

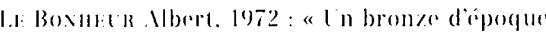
pranskorienne representant Vaitreya m. Arts Isiatirues: 25, p. 129-154.

1.1. Sherman l:.. 1969) : Incient Cambodian Siculpture. Sow Jork. The Isia Society. 
Laxorut: Robert, 1999: Ruhless Compassion IIralhful Deities in I:arly Indo-Tibetan Esoleric Buddhist 1rl. London. Serindia Publications.

l.oвo Wibke. 1997: " I:image de Herajra el le boud-

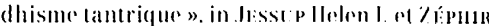
Thierm frod.). Ingkor et dix siecles d'arl khmer. Paris. Réunion des musiós nationaux, p. 70)-7s.

— 2006: « Mahạyāna- Und Vajraỵāna-Buddls ismus in der \% \% von dayalvarman VII », in l.obo Wibke ct Jisst. Plleten I. léd.l. 2006, p. 69-73.

lobo Wibke at Jisstep Helen 1. (éd.) 2006 Ingkor. Göaliches lirbe Kambodschas. Bonn "t \%ürich, Kunst- und Ausstellungshallo der Bundescepublik Deutsehland or Vuseum Rienbergs.

Loxg Sisu. s. d. : Dictionnaire du khmer ancien alapres les inseriptions du cambodge du v" I $\mathrm{rr}^{\prime}$ siecles), Phonom Penh. Phnom Penh Printing llouse.

- 1993 : bitudes de toponymie en ancien khmer. Cahiers d'itudes fianco-rambodgiens. n" Phomom Penh. Centre culturel el de cooperation linguistique, Servier rulturel de l'Ambatssalde de liance.

- 2007 : "les toponymes an khmer ancion". 1serenie 19. p. 15.74.

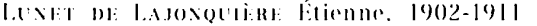
Incentaire descriptif des monumen's du Cambodege. 3 vol.. Paris. l. leroux.
Marmanx be Marie-Therese, 1975: Introduction a l'iconographie du tântrisme bouddhique. Paris. 1. Maisonneuse.

Pa. Pratapaditya, 200t: Asian Irt at the Morton Simon 1/useam, IIl. Ire from sri lonka so Southeast Asia. New Ilaten ol Iondon. Vale Iniversily Press.

Pot Saveros. 2004: Dictionnaire vieux khmer-francais-anglais / In Old Khmer-French-linglish dictionary. Paris, lillarmallan.

Powers John 2007: "Vajrayaña Buddhism" "Vajrayanat pantheon": "Vajrayãna practice". in Krowx l)amien ef Proibisu (harles S. (éd.). lincyclopedia of Buddhism. Iondon, Routledge. p. $774-785$ : p. $785-789$; p. $789-793$.

Roviton Vittorio, 2005: Images of the (jods: Khmer Bythology in Cambodia. Thailand and laos. Bingkok, River Books.

SAxulnsox Alexis, 1992: "The Doctrines of the

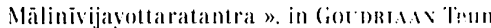
feid.), Ritual and Speculation in laterly Tantrism. Studies in llonor of Indre Padoux. Now Sork. State I niversity of . Sow York, p. 281-312.

- 1904: " Vajrayana: Origin and Function ", in Buddhism into the fear 2000): International (onference Procesedings. Bangkek. I)hammakisya Fioundation, p. $87-102$.

- 2003-2004: "The Saiva Relisgon among the Khmers. Part 1 ", Bl:Fl:090-91. p. 349-462
Sisatr fimile, 1883: " Cne inscription bouddhique du (ambodge" "|K. IIII, Reene archeologique mars-avril, p. 182-192.

SHannock Peter 1).. 2006: "The Buddhist pantheon of the Bayon of Angkor: an historical and all historical reconstruction of the Bayon temple and its religious and political roots ". Phl). l.ondon, So:ss.

SNH.l.cirove: 1)avid I... 1985: Indo-Tibetan Buddhism: Indian Buddhists and their Tibetan suceessors. london of Boston. Serindia Publications of Shambala Publication.

Sottrt: Dominique, 2009: "Organisation religieuse" et profane du temple khmer du vol au xull

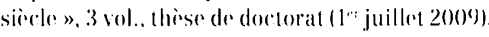
unis. Sorbonne nowrelle Paris 3.

Stchoupack Vadine, Natra lugigia et Rexou louis. 1987 : Dictiomuaire sunskrit-frencereis, Paris, I Vaisonneuve (P’ublications de l'Institut de civilisation indienmen.

Woonwano Miram WV. Jr., 1981: : Tantric Buddhism al Angkor Thom ". Ars Orientalis 12. p. $57-67$.

- 2003 : The Art and Irchitesture of Thailand. leviden or Bostun, l:. J. Brill.

- 2007: "The karandaryuha Sutra and Buddhist Arl in loth-contury Cambodial" in PA1. Pratapaditya réd.J. Buddhist trt. Form is Meraning. Mumbai Marg. p. 70-83.

- 2010 : "Brones Sculptures of Ancient

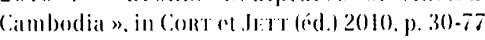

